\title{
Ectopic Expression of Aeluropus littoralis Plasma Membrane Protein Gene AlTMP1 Confers Abiotic Stress Tolerance in Transgenic Tobacco by Improving Water Status and Cation Homeostasis
}

\author{
Walid Ben Romdhane ${ }^{1,2,+, \ddagger}$, Rania Ben-Saad ${ }^{2}$, Donaldo Meynard ${ }^{3}$, Jean-Luc Verdeil ${ }^{3}$, \\ Jalel Azaza ${ }^{2}$, Nabil Zouari ${ }^{2}$, Lotfi Fki ${ }^{4}$, Emmanuel Guiderdoni ${ }^{3}$, Abdullah Al-Doss ${ }^{1}$ \\ and Afif Hassairi $1,2, *, t, \ddagger$ \\ 1 Plant Production Department, College of Food and Agricultural Sciences, King Saud University, \\ P.O. Box 2460, 11451 Riyadh, Saudi Arabia; walid.brm3@gmail.com (W.B.R.); aaldoss@ksu.edu.sa (A.A.-D.) \\ 2 Biotechnology and Plant Improvement Laboratory, Centre of Biotechnology of Sfax, University of Sfax, \\ B.P 1177, 3018 Sfax, Tunisia; raniabensaad@gmail.com (R.B.-S.); azazajalel@yahoo.fr (J.A.); \\ nabil.zouari@gmail.com (N.Z.) \\ 3 CIRAD-UMR AGAP (Centre de Cooperation Internationale en Recherche Agronomique pour le \\ Developpement), Avenue Agropolis, 34398 Montpellier CEDEX 5, France; donaldo.meynard@cirad.fr (D.M.); \\ jean-luc.verdeil@cirad.fr (J.-L.V.); emmanuel.guiderdoni@cirad.fr (E.G.) \\ 4 Laboratory of Plant Biotechnology Applied to Crop Improvement, Faculty of Sciences of Sfax, \\ University of Sfax, B.P 802, 3038 Sfax, Tunisia; lotfifki@yahoo.fr \\ * Correspondence: afif.hassairi@gmail.com; Tel.: +966-11-467-6715 \\ + Current Address: Plant Production Department, College of Food and Agricultural Sciences, \\ King Saud University, P.O. Box 2460, 11451 Riyadh, Saudi Arabia. \\ $\ddagger$ These authors are joint co-first authors.
}

Academic Editor: Hikmet Budak

Received: 1 February 2017; Accepted: 20 March 2017; Published: 24 March 2017

\begin{abstract}
We report here the isolation and functional analysis of AlTMP1 gene encoding a member of the PMP3 protein family. In Aeluropus littoralis, AlTMP1 is highly induced by abscisic acid (ABA), cold, salt, and osmotic stresses. Transgenic tobacco expressing AlTMP1 exhibited enhanced tolerance to salt, osmotic, $\mathrm{H}_{2} \mathrm{O}_{2}$, heat and freezing stresses at the seedling stage. Under greenhouse conditions, the transgenic plants showed a higher level of tolerance to drought than to salinity. Noteworthy, AlTMP1 plants yielded two- and five-fold more seeds than non-transgenic plants (NT) under salt and drought stresses, respectively. The leaves of AlTMP1 plants accumulated lower $\mathrm{Na}^{+}$but higher $\mathrm{K}^{+}$and $\mathrm{Ca}^{2+}$ than those of NT plants. Tolerance to osmotic and salt stresses was associated with higher membrane stability, low electrolyte leakage, and improved water status. Finally, accumulation of AlTMP1 in tobacco altered the regulation of some stress-related genes in either a positive (NHX1, CAT1, APX1, and DREB1A) or negative (HKT1 and KT1) manner that could be related to the observed tolerance. These results suggest that AlTMP1 confers stress tolerance in tobacco through maintenance of ion homeostasis, increased membrane integrity, and water status. The observed tolerance may be due to a direct or indirect effect of AlTMP1 on the expression of stress-related genes which could stimulate an adaptive potential not present in NT plants.
\end{abstract}

Keywords: drought and salt tolerance; Aeluropus littoralis; AlTMP1; plasma membrane protein; transgenic tobacco 


\section{Introduction}

Crop yield reduction due to the direct effect of drought, salt, and cold stresses was estimated as high as $70 \%$ [1]. These stresses affect plant growth and development through osmotic stress, nutrient imbalance and the toxic effects caused by an excess of $\mathrm{Na}^{+}$and $\mathrm{Cl}^{-}$ions [2]. Plants can use many mechanisms to alleviate abiotic stresses such as the production of antioxidants and transport or compartmentalization of toxic $\mathrm{Na}^{+}$. The living cells need to maintain their intracellular ion and osmotic homeostasis, which are essential for the activities of many enzymes involved in different physiological processes. Indeed, cells must be able to preserve a high concentration of $\mathrm{K}^{+}$and low concentration of $\mathrm{Na}^{+}$in the cytosol [3]. In the presence of high salinity in the soil, it was shown that plants use mechanisms to maintain ion homeostasis by compartmentalizing the $\mathrm{Na}^{+}$into vacuoles. In addition, plants adjust their osmotic balance by accumulating osmolytes (betaine, glycine, and proline), maintaining succulence and secreting salt [4,5]. These functions are carried out by a battery of proteins that are classified as pumps, carriers, and channels. At the cell level, plants use ion channels and ion transporters to maintain the appropriate concentration of $\mathrm{Na}^{+}$, $\mathrm{K}^{+}$, and $\mathrm{Ca}^{2+}$ in the cell through active and diffusion mechanisms of ion transport (reviewed in [6]). In fact, some genes such as NHX-type antiporters have been isolated and identified to be responsible for removing $\mathrm{Na}^{+}$from the cytoplasm. This mechanism can be performed either by the exclusion of $\mathrm{Na}^{+}$from plant cells (plasma membrane group: SOS1 (NHX7) from Arabidopsis) or by the sequestration of $\mathrm{Na}^{+}$in vacuoles (vacuole group: NHX1-NHX4 from Arabidopsis) [7]. However, other genes have been identified which encode plasma membrane proteins performing the $\mathrm{Na}^{+}$influx into the plant like TaHKT2.1 in wheat [8] and AtHKT1.1 in Arabidopsis thaliana [9]. TaHKT2.1 was shown to co-transport $\mathrm{K}^{+}$and $\mathrm{Na}^{+}$in yeast and Xenopus oocytes [8]. During the last decade, genes responsible for ion transport were identified. These include the nonselective cation channels (NSCCs), ion transporters and membrane-potential modulators (such as a proton pump) $[10,11]$. The NSCCs can be divided into: cyclic-nucleotide-gated NSCCs (CNGSs), amino-acid gated NSCCs (AAG-NSCCs) and reactive-oxygen-species-activated (ROS) [10].

A small hydrophobic peptide (55 amino acids) encoded by the PMP3 gene was suggested to be involved in preventing $\mathrm{Na}^{+}$entry into the cells [12]. This plasma membrane protein modulates the membrane potential in yeast $[12,13]$. Due to membrane hyperpolarization, the $\Delta p m p 3$ yeast mutant is sensitive to both $\mathrm{Na}^{+}$and the cationic hygromycin B [12]. PMP3 are small plasma membrane proteins which are highly conserved in bacteria, yeast, nematode and plants [14]. Many homologs to PMP3 were found in barley [15], rice [16], wheat [17], maize [3], red sage [18], Arabidopsis [19] and the halophyte Aneurolepidium chinense [20]. The transcription of all these genes was shown to be induced by low temperature, salinity, and $\mathrm{H}_{2} \mathrm{O}_{2}[15,16,19,20]$. Proteins of the PMP3 family contain two highly hydrophobic domains, linked together by a short loop, and appear to be localized in the cell membrane [21]. Using the TMHMM server (TMHMM 2.0), it was shown that both the $\mathrm{N}$ - and C-termini of wheat WPI6 protein (PMP3 homolog) are located in the membrane whereas the internal short loop is cytoplasmic [17]. Several analyses of complementation in yeast pmp3 mutants have shown that the expression of many plant homologs such as OsLTi6a, OsLTi6b from Oryza sativa, AtRCI2a, AtRCI2b from A. thaliana, AcPMP3.1 from A. chinese, PutPMP3.1, PutPMP3.2 from Puccinellia tenuiflora, ZmPMP3.1 from Zea mays, MsRCI2A from Medicago sativa, and MtRCI2(A-C) from Medicago truncatula could functionally complement the salt sensitivity resulting from PMP3 deletion [3,22,23]. In Arabidopsis, the disruption of $A t R C I 2 a$ led to salt sensitivity due to the over-accumulation of $\mathrm{Na}^{+}$in the cells [24]. Furthermore, transgenic Arabidopsis overexpressing AtRCI2a showed an enhanced salt-tolerant phenotype by decreasing $\mathrm{Na}^{+}$uptake [25]. It was also shown that overexpression of Musa paradisica $M p R C I$ in the AtRCI2a knockout mutant increased $\mathrm{Na}^{+}$tolerance and $\mathrm{K}^{+}$sensitivity under $\mathrm{NaCl}$ or $\mathrm{KCl}$ treatments, respectively. This result suggests that $M p R C I$ can affect the $\mathrm{Na}^{+} / \mathrm{K}^{+}$flux in the plant [26]. On the other hand, overexpression of ZmPMP3.1 in Arabidopsis enhanced plant growth under salt stress by decreasing the oxidative cell damage and possibly regulating ion homeostasis [3]. More recently, it has been shown that over-expression of $M s R C I 2 A$ in alfalfa resulted in improved 
salt tolerance [22]. The overexpression of OsLTI6b in rice enhanced its tolerance to cold stress but had no effect on salinity or drought tolerance [27]. On the other hand, overexpression of OsRCI2-5 (sharing 60\% sequence identity with OsLti6b) increased drought tolerance [28]. Altogether, these data suggest that PMP3 family proteins play an important role in maintaining intracellular ion homeostasis, membrane potential, and membrane organization. Despite high similarities between PMP3 genes, different studies reported that these genes are not functionally equivalent.

Although the majority of plants cannot thrive in the presence of high concentration of salt in the soil, the extremophile halophytes can grow and reproduce in these conditions. These halophytes can be used as valuable model plants and genetic resources to decipher the molecular, biochemical and physiological mechanisms of salt tolerance in plants. This strategy will contribute to advance the improvement of salt tolerance in economically important crops. Indeed, the identification of the key genes and promoters from these extremophiles could be used to engineer plant abiotic stress tolerance either by overexpressing, silencing or editing [29]. Wild relatives of cultivated species are also a hopeful alternative source of tolerance genes: as an example, a novel stress-inducible membrane protein TdicTMPIT1 predicted to be localized in the chloroplast was recently isolated from drought tolerant wild emmer wheat and not present in modern wheat cultivars, Kiziltan, has been shown to be an interesting candidate with a putative role in stress signaling [30]. To eventually improve the tolerance to abiotic stresses in cereals, we are using the halophyte grass A. littoralis as a source of candidate genes and their promoters. This extremophile previously described by [31], is a perennial $\mathrm{C} 4$ grass, can secrete $\mathrm{NaCl}$ by salt glands and has $(2 n=2 X=10)$ chromosomes with an estimated genome size of 349 Mega bp. To decipher the mechanisms behind salt tolerance in this halophyte plant at the genomic level, we have isolated 492 ESTs (expressed sequence tag) from a differentially expressed cDNA library prepared by suppression subtractive hybridization (SSH) using salt-stressed roots [31]. These ESTs shared significant similarities with sequences from rice, maize and sorghum [31] and the functional analysis of their full-length genes in tobacco can allow the identification of the key candidate genes to be used for crop stress tolerance improvement. As a demonstration of this strategy, we previously reported the isolation of the AISAP gene and its promoter [32,33]. The constitutive expression of AISAP in tobacco, wheat, and rice has resulted in enhanced tolerance to drought, salinity, cold, heat, and oxidative stresses [32,34,35].

To decipher the efficient regulation systems for ion homeostasis and osmoregulation under salt stress developed by the halophyte grass $A$. littoralis, we isolated and characterized a gene (AlTMP1, KY321744) encoding a PMP3 protein. In A. littoralis, AlTMP1 was shown to be induced by abscisic acid (ABA), cold, salt and osmotic stresses. We have found that the expression of the AlTPM1 gene in tobacco improved tolerance more efficiently to continuous drought than to salinity under greenhouse conditions. In addition, these transgenic tobacco plants showed significantly improved tolerance to heat and cold stresses. Interestingly, AlTMP1 plays a role in maintaining high membrane stability. Finally, AlTMP1 accumulation was shown to alter the expression some stress related genes under both control and stress conditions and likely primes the plants to tolerate stresses.

\section{Results}

\subsection{Isolation and Sequence Analysis of the AlTMP1 Gene}

The differentially expressed AlTMP1 full-length cDNA clone (accession number in GenBank: KY321744) was isolated following the screening of an SSH cDNA library previously prepared [31] from roots of $A$. littoralis plants stressed with $300 \mathrm{mM} \mathrm{NaCl}$ during 15 days. The sequence analysis revealed that AlTMP1 cDNA is $514 \mathrm{bp}$ long, including a complete open reading frame (ORF) of $174 \mathrm{bp}$ with 5'-UTR and 3'-UTR regions of 67 and $273 \mathrm{bp}$, respectively (Figure 1). The comparison between AlTMP1 cDNA and its amplified genomic sequence revealed that the gene contains two exons separated by one intron of 109 bp (Figure S1). AlTMP1 encodes a 57-amino-acid protein with a predicted molecular weight of $6.23 \mathrm{kDa}$, a pI of 4.75 
(http://web.expasy.org/compute_pi/) and contains a conserved domain with high homology (E-value: $\left.9.00 e^{-14}\right)$ to the pfam01679 (https:/ / www.ncbi.nlm.nih.gov/Structure/cdd) (Figure S2A). The search for the presence of predicted transmembrane helices in AlTMP1 protein using the TMHMM 2.0 server [36] revealed the presence of two $\alpha$-helices transmembrane domains TM1 (from aa10 to aa27) and TM2 (from aa34 to aa56) which are separated by one short loop of six amino acids (Figure S2B). In addition, the TMHMM 2.0 analysis predicted that the N-terminal of 9aa length is outside the membrane (Figure S2B). Moreover, by analyzing the hydropathy using the software "protparam" (http://web.expasy.org/protparam/), the AlTMP1 polypeptide seems to be highly hydrophobic as its predicted grand average of hydropathicity (GRAVY) value is 1.225 (Figure S2C).

\section{CDNA of AITMP1 gene and its protein}

$\begin{array}{llllllll}10 & 20 & 30 & 40 & 50 & 60 & 70 & 80\end{array}$

$\ldots|\ldots| \ldots|\ldots| \ldots|\ldots| \ldots|\ldots| \ldots|\ldots| \ldots|\ldots| \ldots|\ldots| \ldots|\ldots| \ldots|\ldots| \ldots|\ldots| \ldots \mid$ AGGGCAGAGGAGCTTTTGTGCTCAAGCAAGTAGCAGGCGGTGAGTTGTTCTCCGTCGGTAGTCGGCCATGGCGGACGAAG

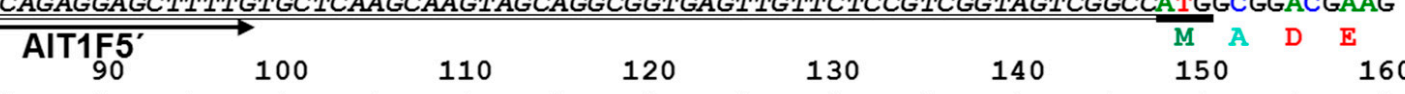

$\ldots \ldots|\ldots| \ldots|\ldots| \ldots|\ldots| \ldots|\ldots| \ldots \ldots|\ldots| \ldots \ldots|\ldots| \ldots|\ldots| \ldots|\ldots| \ldots|\ldots| \ldots \mid$ GGACGGCCAACTGCGTCGACATCCTCATCGCCATCATCCTGCCGCCGCTCGGCGTCTTCCTCAAGTTCGGATGCGGGCAC $G \quad T \quad A \quad N \quad C \quad V \stackrel{D}{-} \stackrel{L}{-}$ TM1 domain

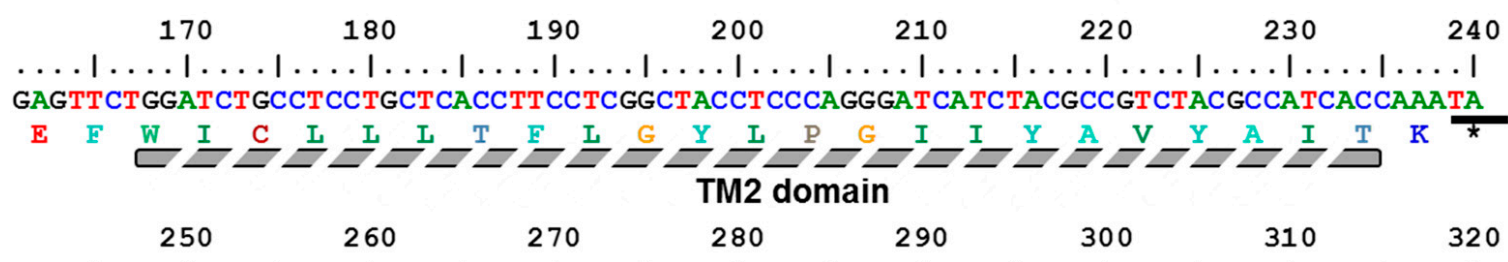
$\ldots|\ldots| \ldots|\ldots| \ldots|\ldots| \ldots|\ldots| \ldots|\ldots| \ldots|\ldots| \ldots|\ldots| \ldots|\ldots| \ldots|\ldots| \ldots|\ldots|$ | $\ldots \mid \ldots$ GACCACACCTTCAAGTAAAGCTGCTCAAGGATTCGTACTGCTGGTGTCTGGTGGTGATGTAAACTATGTGTGGGATCATC

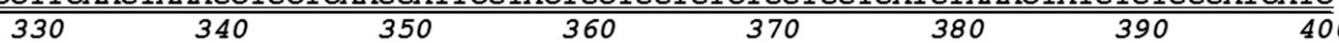

$\ldots|\ldots| \ldots|\ldots| \ldots|\ldots| \ldots|\ldots| \ldots|\ldots| \ldots|\ldots| \ldots|\ldots| \ldots|\ldots| \ldots|\ldots| \ldots|\ldots|$ CAGGACTTETACTTGTCTGAGTGCATGCTCCACTTCTTGTTCTTGTAATTTCCTTTCTAATTCTAGCAGCCGTGTTCACA $\begin{array}{llllllll}410 & 420 & 430 & 440 & 450 & 460 & 470 & 480\end{array}$

$\ldots|\ldots| \ldots|\ldots| \ldots|\ldots| \ldots|\ldots| \ldots|\ldots| \ldots|\ldots| \ldots|\ldots| \ldots|\ldots| \ldots|\ldots| \ldots|\ldots|$ TACATATGTAGTTCCCTCTGGATCATGCGTGTGCGGAACCTACCTGCTATGCTCCCGTTCTTGTTCATGTAATTTCCTTT 490 500 510 AIT1R3

$\ldots|\ldots| \ldots|\ldots| \ldots|\ldots| \ldots \mid \ldots$

CTAATTCTAGCAGCTGTGTTCGTATGTTTGATTT

Figure 1. Full-length cDNA sequence and predicted protein sequence of AlTMP1. The amino acid sequence is shown in single code letters beneath the cDNA sequence. Translational start codon (ATG) and stop codon (TAG) are underlined. The $5^{\prime}$ and $3^{\prime}$ non-coding sequences are double underlined. The conserved transmembrane domains (TM1 and TM2) are highlighted in gray. The sequence was analyzed with BioEdit 7.2.5 programs and the TMHMM 2.0 server. The * design the stop codon terminating AlTMP1 protein synthesis.

The search of NCBI database using blastp revealed a significant high identity between AlTMP1 and other genes encoding PMP3 proteins isolated from monocot and dicot plants (ZmPMP3.1 to ZmPMP3.8 from Z. mays [3], OsLti6a and OsLti6b from O. sativa [16], AcPMP3.1 and AcPMP3.2 from Leymus chinense [20], PutPMP3.1 and PutPMP3.2 from P. tenuiflora [23], BLT101.1 and BLT101.2 from Hordeum vulgare [15], WPI6 from Triticum aestivum [17], ESI3 from Lophopyrum elongatum [37], $M p R C I$ from Musa paradisiaca [26,38], AtRCI2a and AtRCI2b from A. thaliana [39], MsRCI2A from M. sativa [22], MtRCI2A and MtRCI2B from M. truncatula [22]) as well as to the PMP3 from Saccharomyces cerevisiae [12] (Figure S3). Comparison of the amino acid sequences of 25 PMP3 genes isolated from a monocot and dicot plants revealed that the transmembrane domains were highly conserved, in particular, the pfam01679 domain. However, the size of these genes was different due to the variable lengths of the C-and N-terminal regions (Figure S3). To study the evolutionary 
relationships between AlTMP1 and its homologs, a phylogenetic tree was constructed by using the MEGA 6 program and the Neighbor-joining method with 1000 replicates. Six highly homologous genes to the AlTMP1 were predicted (Figure 2). The two nearest homologs were found in O. sativa, OsLTI6b (AAT37942.1) and Z. mays, ZmPmP3.1 (NP001107634), with a high identity percentage of $87.7 \%$ and 86.4\%, respectively (Figure 2). Four others homologs were found in Z. mays (ZmPmP3.7 and ZmPmP3.8) and Leymus chinensis (AcPmP3.1 and AcPmP3.2) with a lower identity ranging between $81 \%$ and $84 \%$, whereas, for other $P M P 3$ genes from the remaining dicots and monocots plants, the percentage identity was much lower, ranging from $60 \%$ to $80 \%$. Apart from the plant homologs, the AlTMP1 showed $31 \%$ identity to the yeast $P m p 3 p$ gene.

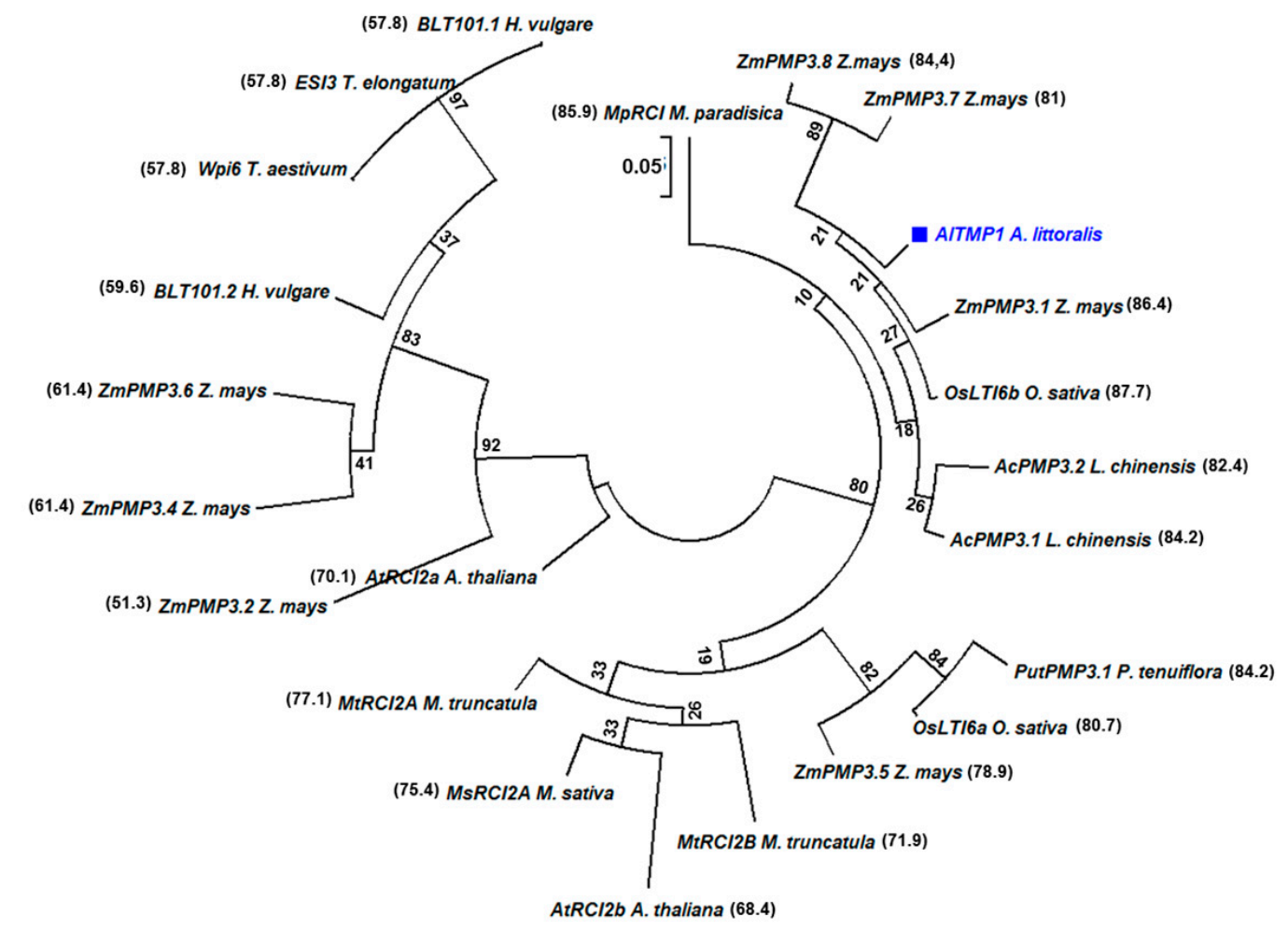

Figure 2. Phylogenetic analysis of AlTMP1 and its homologs from different plants. The phylogenetic tree was constructed with the full-length amino acid sequences of PMP3 family proteins in Z. mays, O. sativa, P. tenuiflora, H. vulgare, T. aestivum, Thinopyrum elongatum, L. chinensis, Musa, A. thaliana, M. truncatula and M. sativa. The MEGA 6 program and the Neighbor-joining method with 1000 replicates were used to generate the phylogenetic tree. Numbers are bootstrap values. The percentages of identity between AlTMP1 gene and different PMP3 proteins are indicated between brackets (\%). The AlTMP1 gene isolated in this study is in blue font.

\subsection{AlTMP1 is a Plasma Membrane Protein}

By using the hydrophobicity plotting or the algorithms TMHMM, it was predicted the presence of two conserved putative transmembrane domains in AlTMP1 protein. The green fluorescent protein (GFP) (pCAMBIA2300::GFP) and the GFP::AlTMP1 fusion proteins (pCAMBIA2300::GFP::AlTMP1) were transiently expressed in onion epidermal cells, and their subcellular localizations were visualized by confocal microscopy. In control cells transformed with the GFP construct, the fluorescence was observed in the cytoplasm, nucleus, and cell membrane, while, in cells expressing the GFP::AlTMP1 fusion gene, the GFP signal was observed only in the cell membrane, suggesting that AlTMP1 was localized to the plasma membrane (Figure 3). 


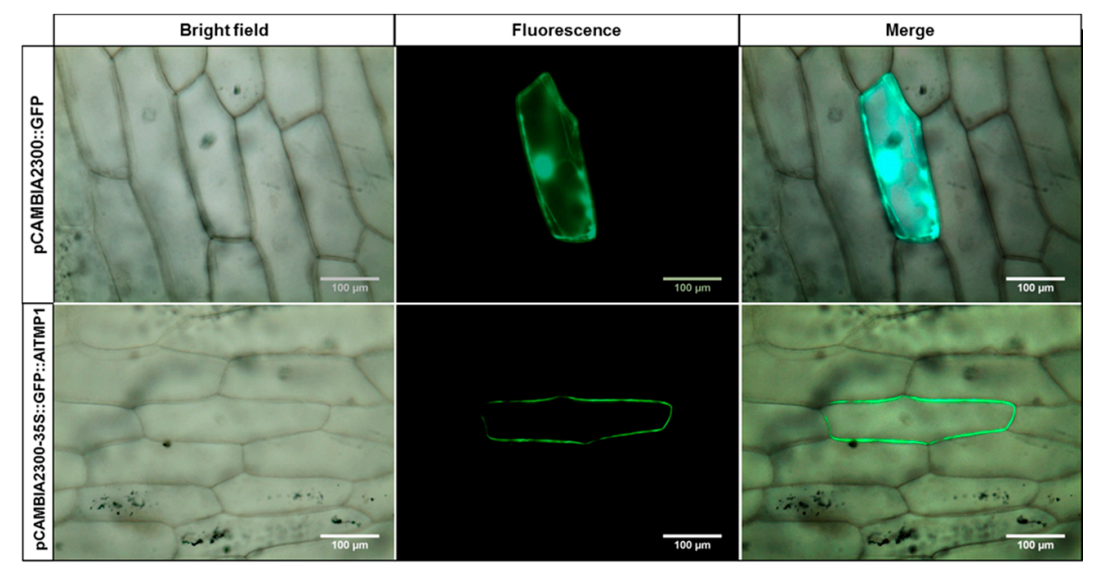

Figure 3. Subcellular localization of AlTMP1::GFP in onion epidermal cells. 35S::GFP and 35S::GFP::AlTMP1 fusion constructs were transiently expressed in onion epidermal cells using particle bombardment. The onion epidermal cells expressing GFP were set as control. The fluorescent signals were examined by confocal microscopy $36 \mathrm{~h}$ after bombardment. The images of onion epidermal cells expressing 35S::GFP::AlTMP1 fusion were taken in a superposition of bright and fluorescence vision (right), fluorescence field vision (center), and bright light vision (left). Bar $=100 \mu \mathrm{m}$.

\subsection{AlTMP1 Transcription Responds to Abiotic Stresses}

The AlTMP1 transcript abundance was determined by performing qRT-PCR on total RNA isolated from A. littoralis plants treated with different abiotic stresses (salt, osmotic and cold) and to hormonal stress (ABA). PEG 8000 20\% treatment stimulates an early accumulation of AlTMP1 transcripts up to 10-fold higher than that in control plants, following two hours of stress application. As to the $\mathrm{NaCl}$, ABA, and cold treatments, significant increases of AlTMP1 transcripts are observed only after $4 \mathrm{~h}$ from the beginning of stress application (Figure 4). The maximum relative expression levels of AlTMP1 transcripts were observed following ABA stress (23-fold higher than the control treatment) and PEG $20 \%$ treatment (13-fold higher than the control) after $6 \mathrm{~h}$ (Figure 4). These results indicate that the AlTMP1 gene is clearly regulated by abiotic and hormonal stresses in A. littoralis. They also suggest that the AlTMP1 is more sensitive to treatments imposing osmotic stress than those triggering ionic stresses and that its regulation is ABA-dependent.

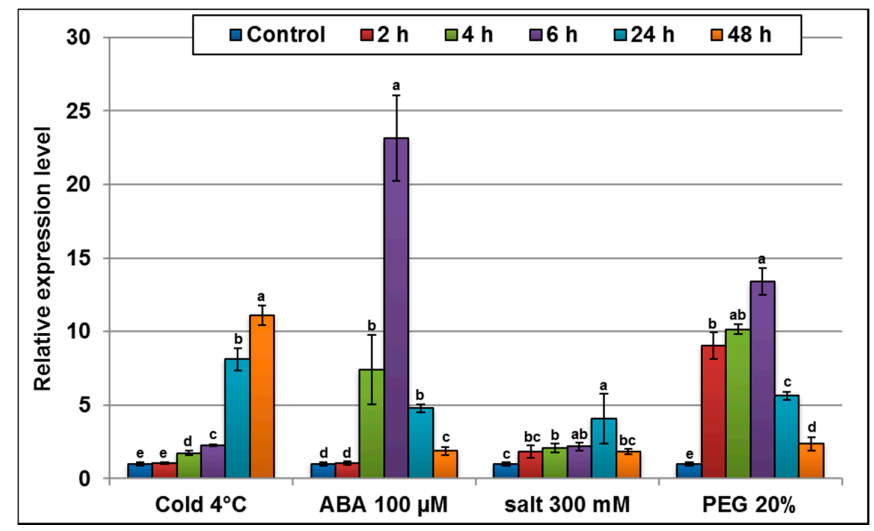

Figure 4. qRT-PCR analysis of AlTMP1 transcripts in A. littoralis plants challenged with various stresses. Two-month-old $A$. littoralis plants were treated with $300 \mathrm{mM} \mathrm{NaCl}, 4{ }^{\circ} \mathrm{C}, 20 \%$ PEG 8000 and $100 \mu \mathrm{M}$ abscisic acid (ABA) for 2, 4, 6, 24 and $48 \mathrm{~h}$. The rRNA18s gene was used as an internal control. Data from qRT-PCR experiments were analyzed according to the $2^{-\Delta \Delta C t}$ method. Vertical bars indicate standard deviation calculated from three replicates. Values are mean \pm s.e. $(n=3)$. Means denoted by the same letter did not differ significantly at $p<0.05$. 


\subsection{AlTMP1 Enhances Abiotic Stress Tolerance in Transgenic Tobacco}

To further investigate the role of AlTMP1 in conferring tolerance to salinity, drought, and cold/heat stresses, we generated transgenic tobacco plants expressing AlTMP1 under the control of the CaMV-35S promoter (Figure 5A). Three independent transgenic tobacco lines, accumulating AlTMP1 transcripts at different levels were selected (L1, L2, and L3). The presence of AlTMP1 gene in tobacco transformants was confirmed by PCR and its integration into the genome was demonstrated by sexual transmission to $\mathrm{T} 1$ and $\mathrm{T} 2$ progenies (Figure $5 \mathrm{~B}$ ). The constitutive expression of AlTMP1 in the selected transgenic lines was evaluated by semi-quantitative RT-PCR analyses (Figure 5C). Two transgenic lines, L2 and L3, respectively, the highest and lowest AlTMP1 expressers, were selected for stress assays under in vitro and greenhouse conditions (Figure 5C).

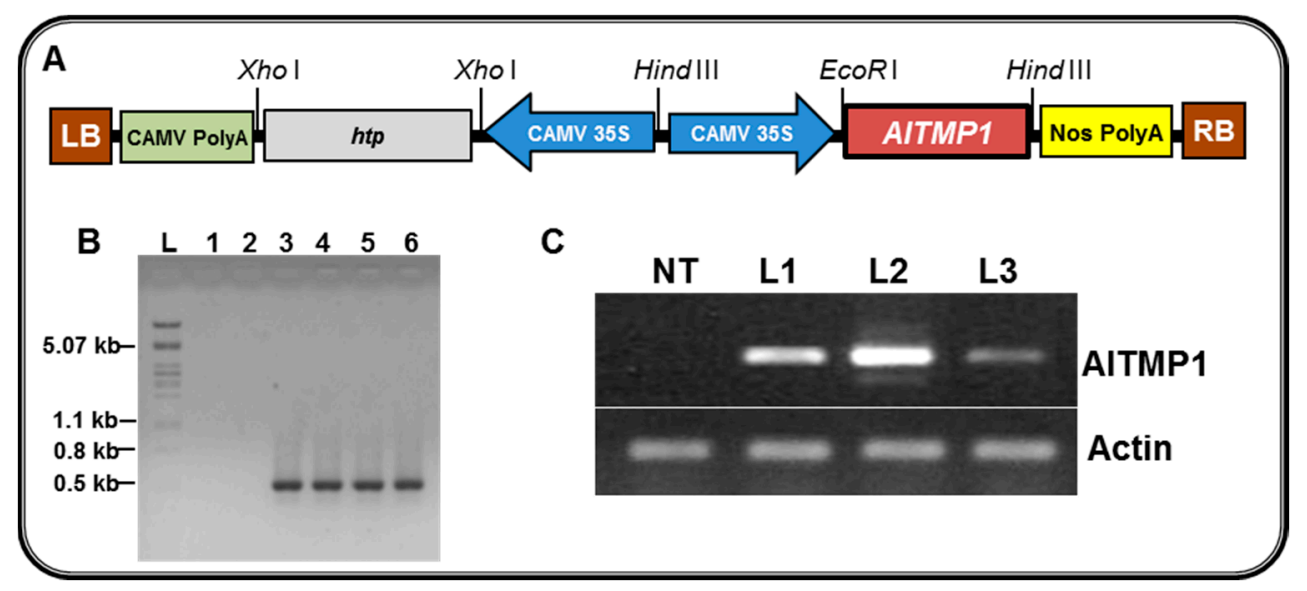

Figure 5. Molecular analysis of T2 transgenic tobacco lines (L1, L2, and L3) expressing AlTMP1. (A) Schematic map of the T-DNA inserted into the binary vector pCAMBIA1390::AlTMP1, used for tobacco transformation; LB: left border T-DNA repeat; RB: right border T-DNA repeat; $h p t$ : gene codes for hygromycin phosphotransferase which detoxifies the antibiotic hygromycin B; (B) PCR amplification products from T2 transgenic and non-transgenic (NT) tobacco plants. Genomic DNA of NT and transgenic tobacco lines was used to amplify AlTMP1 gene with specific primers; lane 1: $\mathrm{ddH}_{2} \mathrm{O}$; lane 2: NT tobacco DNA; lanes 3-5: transgenic clones L1, L2, and L3 DNA; lane 6: pCAMBIA1390::AlTMP1 binary vector DNA used as positive control; lane L: Lambda DNA PstI Marker; (C) Expression pattern of the AlTMP1 gene in transgenic lines (L1, L2, and L3). The RT-PCR analysis was performed with AlTMP1 specific primers using the RNA isolated from the transgenic lines and NT plants. Actin amplification was used as an internal control.

\subsubsection{Evaluation of Stress Tolerance under In Vitro Conditions}

The tolerance to salt $(\mathrm{NaCl})$ and osmotic (mannitol) stresses of homozygous $\mathrm{T} 2$ seedlings of two transgenic lines, L2 and L3 were first evaluated under in vitro conditions. Seeds of non-transgenic tobacco (NT) and the two homozygous transgenic lines L2 and L3 were germinated on different MS media MS0 (control), MS0s (200 mM NaCl) and MS0m (350 mM mannitol). When using MS0, no significant difference was observed in the rate and the percentage of germination between NT and transgenic seeds, indicating that expression of AlTMP1 gene had no effect on seed germination (Figure 6A,B). In the presence of salt (MS0s: $200 \mathrm{mM} \mathrm{NaCl}$ ) or osmoticum (MS0m: $350 \mathrm{mM}$ mannitol), the germination of NT seeds was delayed by six days compared to that observed in the control medium. Moreover, only $31 \%$ and $13 \%$ of NT seeds were able to germinate following 19 days of salt and osmotic stresses, respectively (Figure 6B). However, delay in seed germination of transgenic lines L2 and L3 was reduced to only four days in both MS0s or MSOm treatments (Figure 6B), with a high percentage of germination ranging from $70 \%$ to $80 \%$. Following germination, the growth of NT seedlings stopped, and leaves appeared small (osmotic stress) or yellow (salt stress). Conversely, shoots and roots of all 
the transgenic seedlings continued to grow normally (Figure 6A). For the higher AlTMP1 expressor line L2, the germination was $77 \%$ and $81 \%$ for salt and osmotic stresses, respectively (Figure 6B). This represents 2.5- and 6-fold enhancements under salt and osmotic stresses, respectively, when compared to NT (Figure 6B). All these results suggest that expression of AlTMP1 can enhance seed germination under salt or osmotic stresses. Interestingly, the improved tolerance conferred by AlTMP1 at the seed germination stage was higher in the case of osmotic stress than for salt stress.

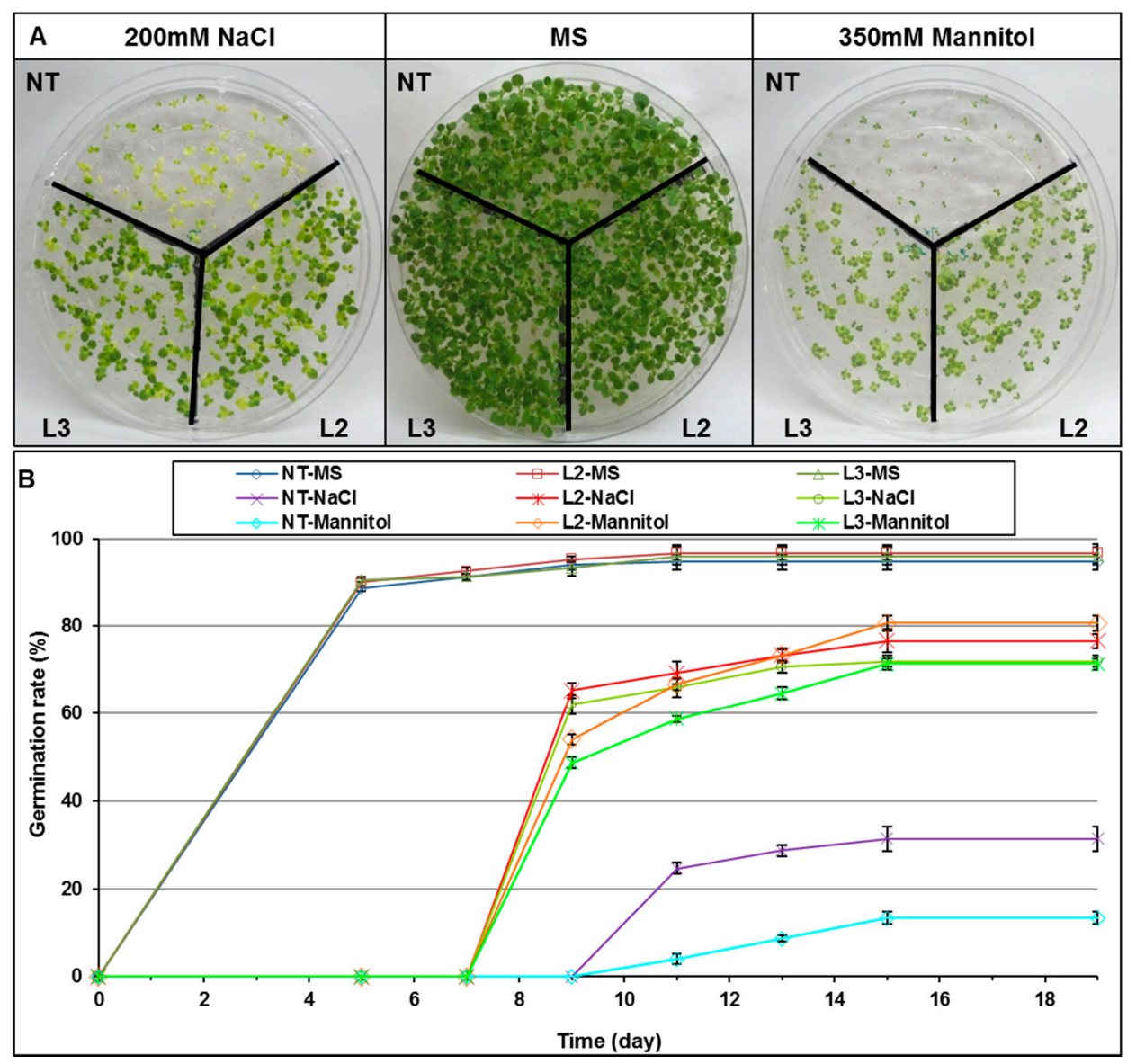

Figure 6. Effect of salt ( $\mathrm{NaCl} 200 \mathrm{mM}$ ) and osmotic (mannitol $350 \mathrm{mM}$ ) stresses on seed germination and plant phenotype in transgenic tobacco plants expressing AlTMP1. (A) Photographs were taken two months after seed germination; (B) Seed germination rates of NT and transgenic plants that are grown on MS medium (control), MS supplemented with $200 \mathrm{mM} \mathrm{NaCl}$ or MS supplemented with $350 \mathrm{mM}$ mannitol. Vertical bars indicate standard deviation calculated from three replicates of 100 seeds each.

To further investigate the effect of salt and mannitol on the root growth, ten-day-old NT and transgenic seedlings germinated on MS0 were transferred to MS0, MS0s ( $\mathrm{NaCl} 100,150$ and $200 \mathrm{mM}$ ), and MS0m (mannitol 200, 300 and $400 \mathrm{mM}$ ). After one month, root and shoot length of NT seedlings were strongly affected by the salt and osmotic stresses, whereas, growth inhibition was less pronounced in transgenic lines (Figure 7A). The roots of plants of the L2 line were 2.5 and 30 fold longer than those of NT under $200 \mathrm{mM} \mathrm{NaCl}$ and $400 \mathrm{mM}$ mannitol, respectively (Figure 7B,C). In addition, the length of $\mathrm{L} 2$ roots was significantly greater than those of $\mathrm{L} 3$ line under these stresses. This better performance of L2 could be ascribed to the higher expression level of AlTMP1 found in this line. 


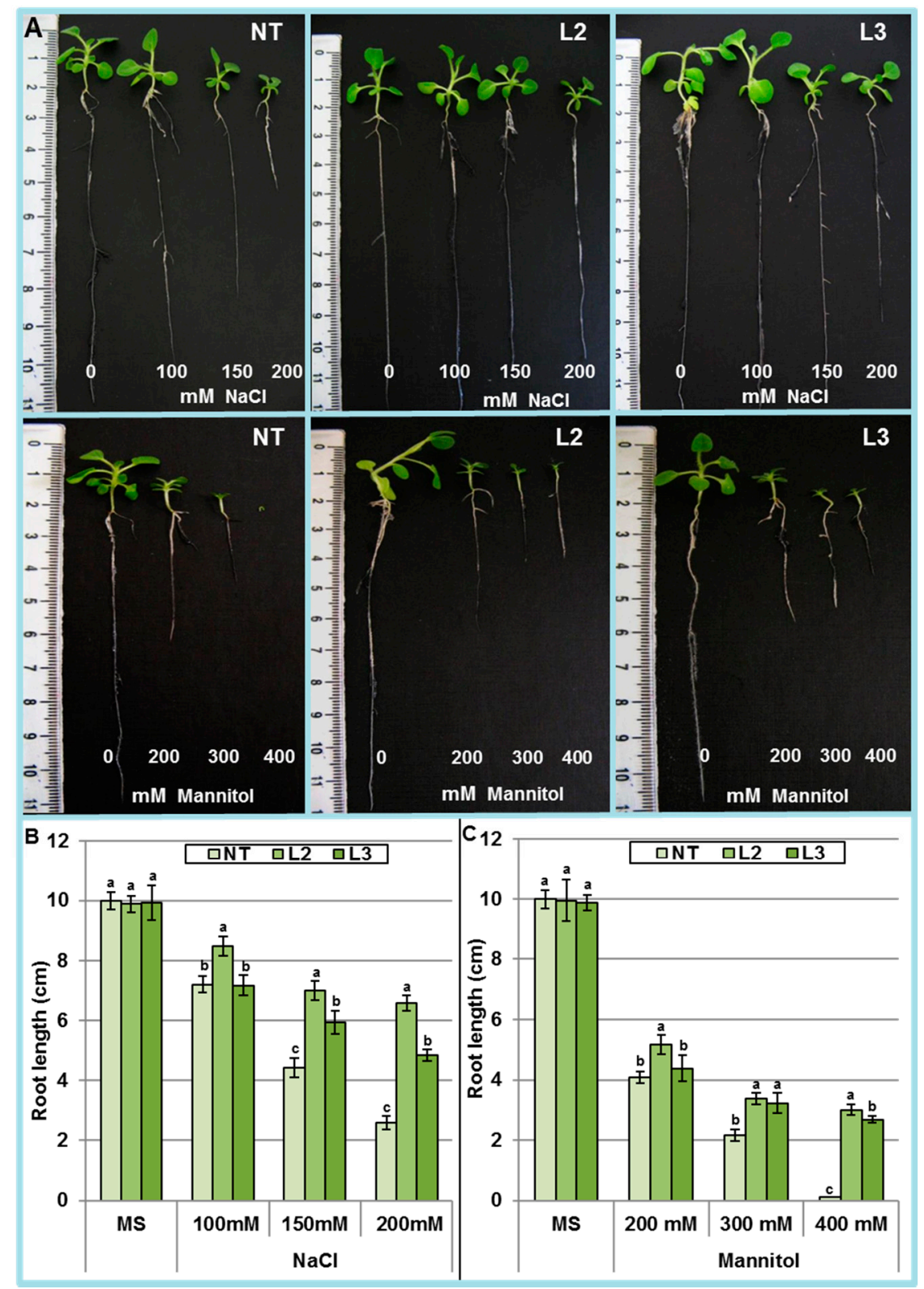

Figure 7. Effect of various concentrations of salt and mannitol on root elongation of non-transgenic (NT) and two AlTMP1 transgenic tobacco seedlings. (A) Photographs were taken four weeks after incubation in vitro; (B) Root length of NT and transgenic seedlings (L2 and L3) grown on MS medium (control) or various concentrations of $\mathrm{NaCl}$; (C) Root length of NT and transgenic seedlings (L2 and L3) grown on MS0 (control) or various concentrations of mannitol. Values are mean \pm s.e. $(n=3)$. Means denoted by the same letter did not differ significantly at $p<0.05$.

Seedlings of NT and transgenic lines after ten days of germination on MS0 were transferred to culture media imposing in vitro osmotic (mannitol $400 \mathrm{mM}$ ), salt $(\mathrm{NaCl} 200 \mathrm{mM})$ or ionic ( $\mathrm{LiCl} 100 \mathrm{mM})$ stresses. Following two months of growth, the whole plant dry weight, the relative water content (RWC), the number of leaves, and the shoot length were evaluated (Figure 8A-H). Whereas the leaves of the NT plants had turned yellowish and wilted, leaves of the transgenic plants were still green leaves, and the shoots were relatively able to elongate (Figure 8A-D). Relative water content (RWC) is probably the most appropriate measure of plant water status. Under osmotic, salt and ionic stresses, transgenic plants retained more water in their leaves than the NT plants (Figure 8E). The RWC for NT plant was only 3\%, 35\% and 49\% under osmotic, $\mathrm{NaCl}$ and $\mathrm{LiCl}$ stresses, respectively (Figure 8E). On the 
other hand, plants of the highest AlTMP1 expressing line (L2) maintained their RWC up to $75 \%, 72 \%$ and $67 \%$ under osmotic, $\mathrm{LiCl}$ and $\mathrm{NaCl}$ stresses, respectively (Figure $8 \mathrm{E}$ ). These results demonstrate that expressing of AlTMP1 in tobacco can enhance the ability of transgenic plants to retain water up to 25 fold more than NT under osmotic stress. Along the same line, the dry weight accumulated by transgenic plants was ten- and three-fold more than that of NT under osmotic and $\mathrm{NaCl}$ stresses, respectively (Figure 8F). In addition, transgenic plants exhibited significantly longer shoot and a higher number of leaves than NT plants under different stresses (Figure 8G,H). These results demonstrated that AlTMP1 gene could enhance the tolerance to $\mathrm{NaCl}$, osmotic and ionic stresses. Again, the level of tolerance attained by the transgenic line seemed correlated with the level of AlTMP1 transcript accumulation. Finally, confirming observations at germination stage, the protection conferred by AlTMP1 appears higher in the case of osmotic stress than for $\mathrm{NaCl}$ and ionic stresses.

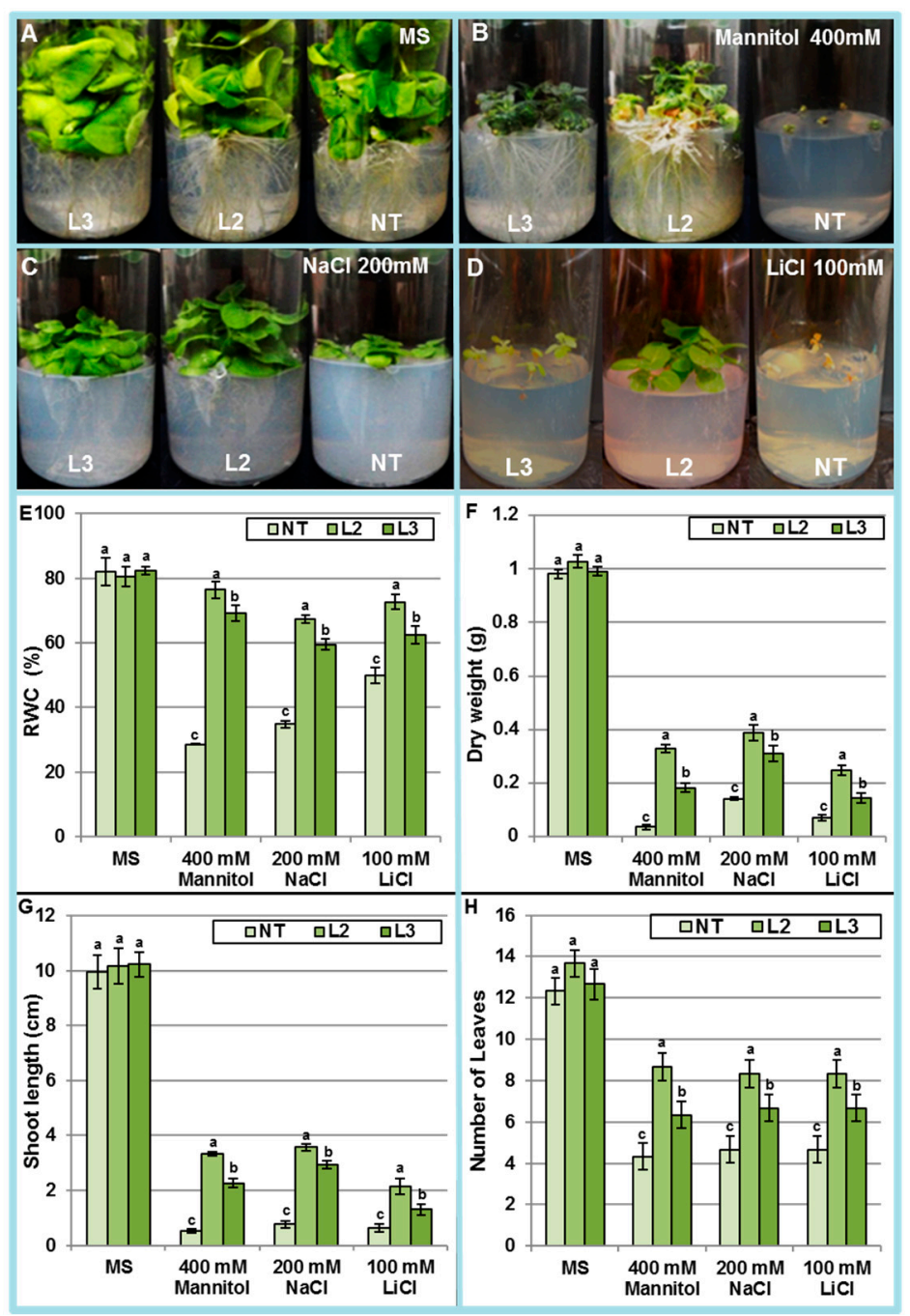

Figure 8. Evaluation of NT and (L2, L3) transgenic lines expressing AlTMP1 grown on MS, mannitol, $\mathrm{LiCl}$, and salt-supplemented media. (A-D) Growth comparison of NT and (L2 and L3) transgenic lines after 60 days in (A) MS; (B) $400 \mathrm{mM}$ Mannitol; (C) $200 \mathrm{mM} \mathrm{NaCl}$ and (D) $100 \mathrm{mM} \mathrm{LiCl}$; (E) Relative water content (RWC) of NT and (L2 and L3) transgenic tobacco lines; (F) Plant dry weight in NT and (L2 and L3) transgenic lines grown on MS, mannitol, LiCl, and salt-containing media; (G) Shoot length of NT and (L2 and L3) transgenic tobacco lines; (H) Number of leaves in NT and (L2 and L3) transgenic tobacco lines. Vertical bars indicate standard deviation calculated from three replications. Values are mean \pm s.e. $(n=3)$. Means denoted by the same letter did not differ significantly at $p<0.05$. 
A detached leaf disc assay was performed to evaluate the chlorophyll content under stresses. This assay can be considered as a reliable index reflecting the damage of the photosynthesis process under stress. When leaf discs were floated on a $\mathrm{NaCl} 700 \mathrm{mM}, \mathrm{LiCl} 400 \mathrm{mM}$ PEG 20\% and $\mathrm{H}_{2} \mathrm{O}_{2}$ $300 \mathrm{mM}$ solution for $72 \mathrm{~h}$, discs of NT plants bleached more dramatically than those of transgenic lines (Figure 9A). These observations were verified by measuring chlorophyll content in leaf discs. When compared to control condition the NT discs retained only $15 \%, 20 \%, 27 \%$ and $31 \%$ of their chlorophyll under $\mathrm{NaCl}, \mathrm{LiCl}, \mathrm{H}_{2} \mathrm{O}_{2}$, and $\mathrm{PEG}$, respectively (Figure 9B). On the other hand, the leaf discs of $\mathrm{L} 2$ line retained $54 \%, 52 \%, 45 \%$, and $32 \%$ of their chlorophyll under PEG, $\mathrm{NaCl}, \mathrm{H}_{2} \mathrm{O}_{2}$, and $\mathrm{LiCl}$, respectively (Figure 9B). Consistent with previous observations, leaf discs of the L2 line displayed higher tolerance to chlorophyll bleaching than those of the L3 line under the different stresses. Altogether, these results support the suggestion that AlTMP1 improves more efficiently tolerance to osmotic stress (the highest chlorophyll retention 54\%) than to other stresses.

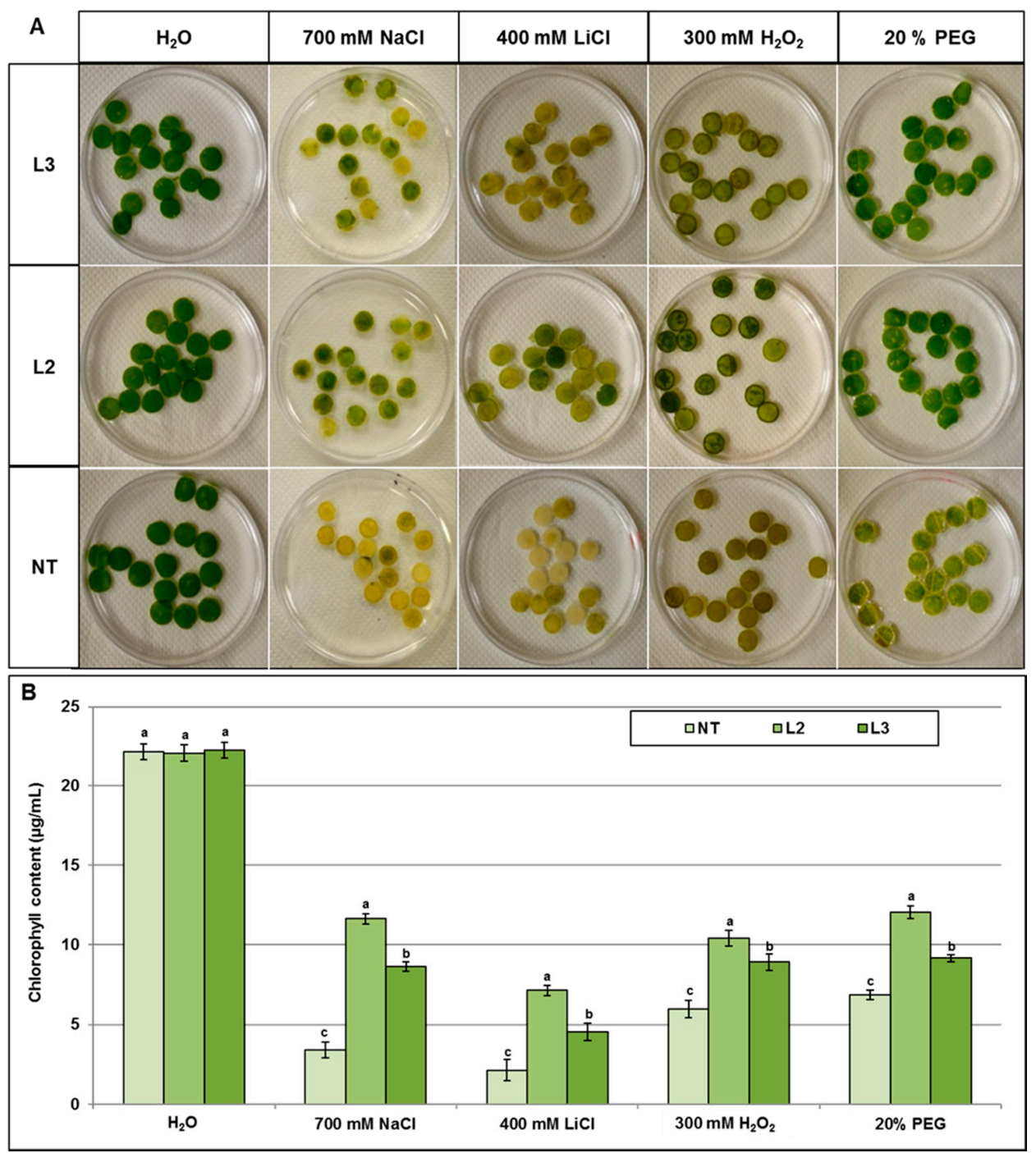

Figure 9. Leaf discs floating assays as an evaluation of ionic and osmotic stress tolerance in transgenic AlTMP1 tobacco lines. (A) The representative picture is showing the phenotypic differences in leaf discs bleaching; (B) Chlorophyll content in the leaf discs of NT and two transgenic lines plants (L2 and L3) after incubation in $700 \mathrm{mM} \mathrm{NaCl}, 400 \mathrm{mM} \mathrm{LiCl}, 300 \mathrm{mM} \mathrm{H}_{2} \mathrm{O}_{2}$ and 20\% PEG. Leaf discs floating in water served as experimental control. After $72 \mathrm{~h}$ of incubation, the chlorophyll content in the leaf discs was measured. Values are mean \pm s.e. $(n=3)$. Means denoted by the same letter did not differ significantly at $p<0.05$. 


\subsubsection{Evaluation of Stress Tolerance under Greenhouse Conditions}

\section{AlTMP1 Confers Tolerance to Cold and Heat Stresses}

As the transcription of the AlTMP1 gene is induced by low-temperature $\left(4^{\circ} \mathrm{C}\right)$, L2 and L3 transgenic lines plants along with NT were confronted to freezing $\left(-20{ }^{\circ} \mathrm{C}\right.$ for two $\left.\mathrm{h}\right)$ and heat $\left(55^{\circ} \mathrm{C}\right.$ for two $\mathrm{h}$ ) stresses. After five days only $13 \%$ and $26 \%$ of NT seedlings were able to recover from freezing and heat stresses respectively (Figure 10A,B). On the other hand, nearly $90 \%$ of transgenic seedlings recovered following the two types of stresses (Figure 10A,B). Consequently, the dry weight of recovered transgenic plants was significantly higher than those of NT plants (Figure 10C).

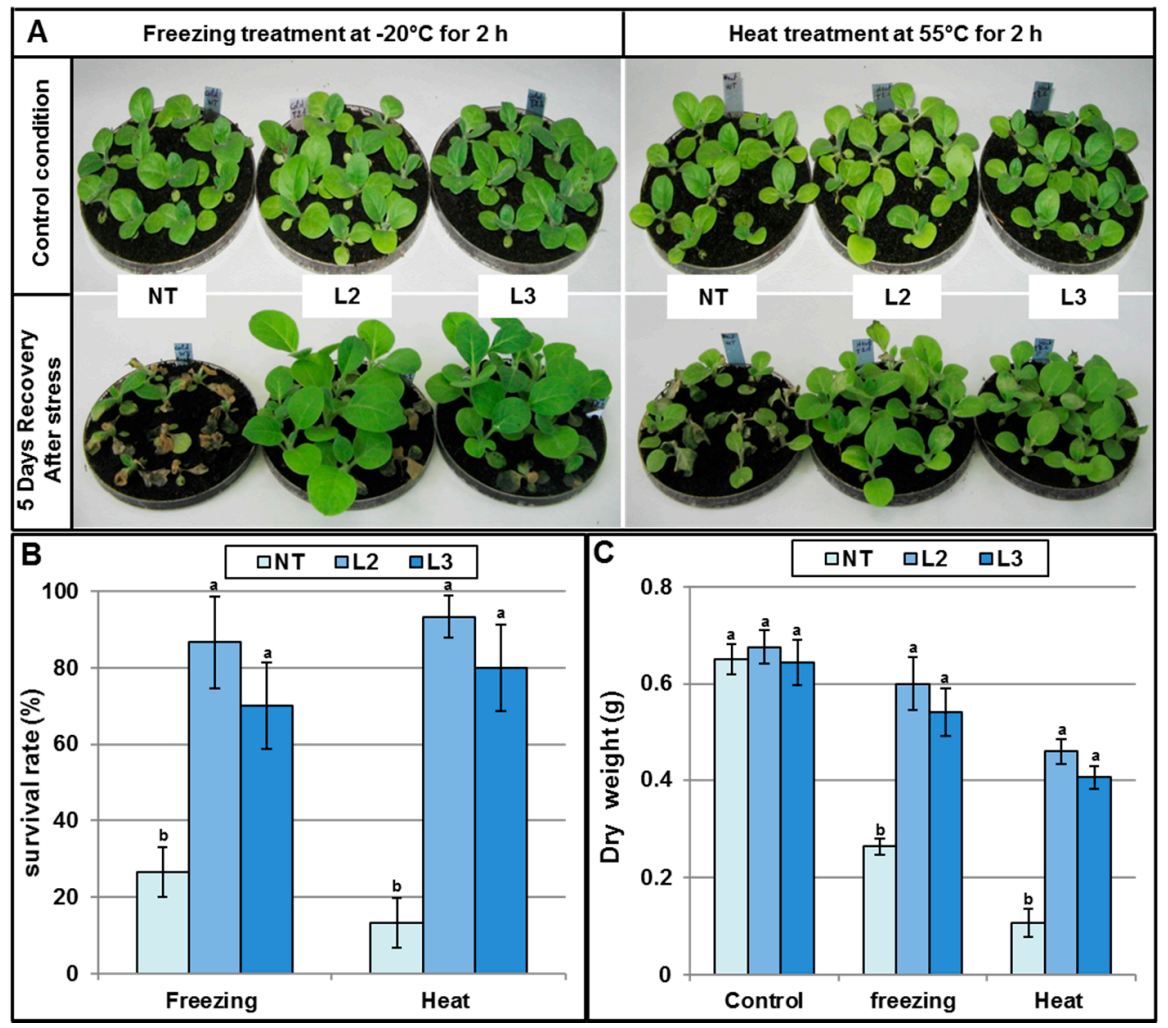

Figure 10. Effect of freezing and heat stresses on non-transgenic and transgenic AlTMP1 plants. (A) Plant phenotype of tobacco non-transgenic (NT) and transgenic plants (L2 and L3) after freezing and heat treatments followed by five-day recovery period at ambient environment; (B) The survival rate five days after the freezing and heat treatment as shown in (A); (C) The dry weight of NT and transgenic plants five days after the freezing and heat treatments. The experiments were repeated three times with similar results. Values are mean \pm s.e. $(n=3)$. Means denoted by the same letter did not differ significantly at $p<0.05$.

\section{AlTMP1 Confers Tolerance to Continuous Salt and Drought Stresses}

Previous in vitro assessment of AlTMP1 transgenic tobacco lines provided a first evidence that they exhibit an enhanced tolerance to salt and osmotic stresses. We further investigated the effect of this gene on growth and seed production under control conditions, drought stress (the RWC of the soil was maintained at $25 \%$ ) or salt stress (irrigation with $\mathrm{NaCl} 250 \mathrm{mM}$ ) until the end of the plant cycle in the greenhouse. Several critical parameters related to plant growth (plant dry weight, root and shoot length, leaf RWC, seed weight, $\mathrm{K}^{+}$and $\mathrm{Na}^{+}$content, membrane stability index and electrolyte leakage) were scored. These parameters were used to evaluate the salt and drought stress tolerance in $\mathrm{T} 2$ homozygous transgenic lines (Figures 11-14). As shown in Figure 11A, the ectopic expression of AlTMP1 does not affect overall plant morphology since no obvious growth or yield penalty was observed between NT 
and AlTMP1 transgenic plants grown under control growth conditions. However, the performance of AlTMP1 transgenic plants was clearly improved under salt and drought stresses. Indeed they were able to continue their growth, reach the flowering stage and set seeds while the NT plants showed a stunted phenotype (Figure 11B,C). The transgenic plants flowered at the same time either under drought stress or control conditions, while under salt stress flowers appeared with a delay of nearly 12 days. On the other hand, compared to control conditions NT flowered with a delay of 18 days under both stresses. Lengths and dry weight of roots and shoots were significantly higher in transgenic plants than in NT under both drought and salt stresses (Figure 12A-D). In addition, as shown in Figure 12E, AlTMP1 enhances the RWC in leaves under drought and salt stresses. Indeed, the RWC was about $67 \%-70 \%$ in transgenic plants compared to $45 \%-55 \%$ in NT plants either under salt or drought conditions. Interestingly, the most striking difference between transgenic and NT plant was observed in seed production. The L2 AlTMP1 transgenic line produced two- and five-fold more seeds than NT under salt and drought stresses, respectively (Figure 12F). The L2 line which accumulates the highest level of AlTMP1 transcripts exhibited a significantly higher tolerance to salt and drought than the lower expressor L3 line.

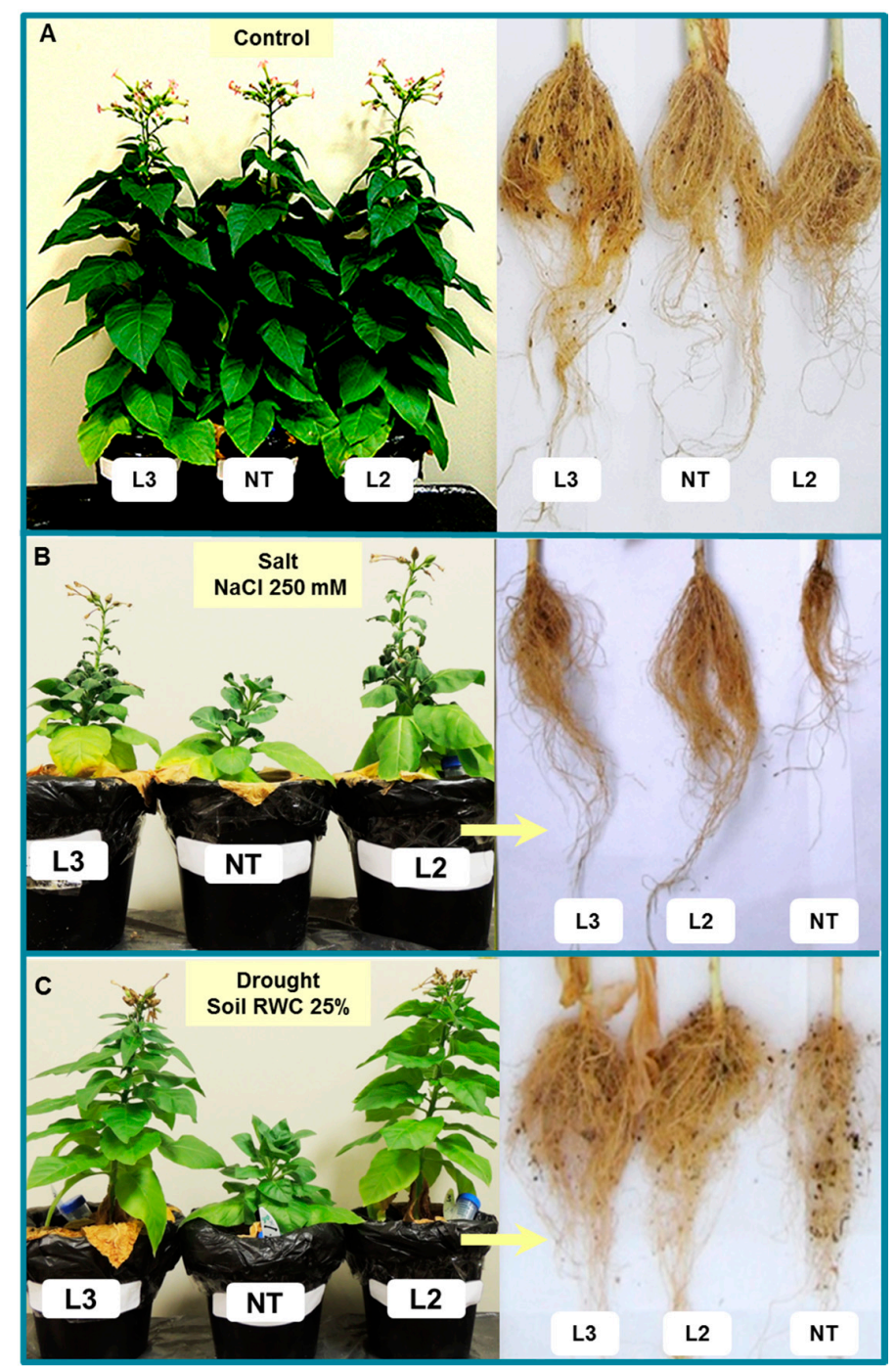

Figure 11. Evaluation of salt and drought tolerance of non-transgenic and AlTMP1 transgenic tobacco plants at adult stage under greenhouse conditions. Phenotypes of NT and transgenic plants which were grown under: normal condition (A); continuous irrigation with a salty solution (250 $\mathrm{mM} \mathrm{NaCl})(\mathbf{B})$; and continuous drought stress (soil RWC of $25 \%$ ) (C). 


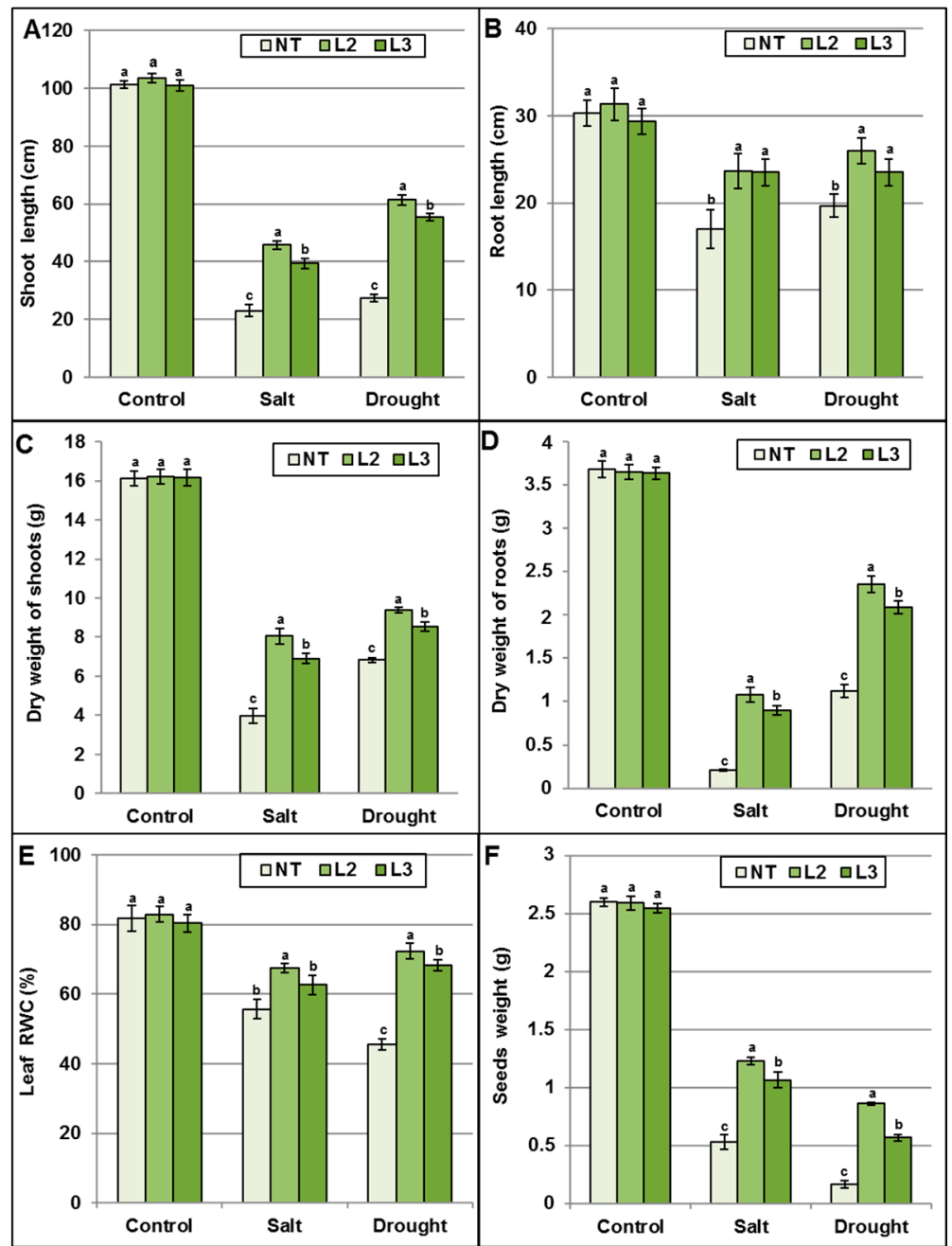

Figure 12. Evaluation of tolerance of non-transgenic and transgenic AlTMP1 (L2 and L3 lines) plants subjected to continuous salt and drought stresses under greenhouse growth conditions: (A) Shoot length; (B) Root length; (C) Shoot Dry weight; (D) Root dry weight; (E) Leaf relative water content (RWC); and (F) Weight of produced seeds (g per plant). Values are mean \pm s.e. $(n=3)$. Means denoted by the same letter did not differ significantly at $p<0.05$.

The concentration of $\mathrm{Na}^{+}, \mathrm{K}^{+}$, and $\mathrm{Ca}^{2+}$ were measured in young and old leaves of the transgenic lines and NT plants following 60 days of salt treatment. No significant difference is observed in $\mathrm{Na}^{+}, \mathrm{K}^{+}$ or $\mathrm{Ca}^{2+}$ accumulation and partitioning in leaves of NT and transgenic plants under control conditions. However, a significant change is seen in the partitioning of $\mathrm{Na}^{+}$and $\mathrm{K}^{+}$in plants grown under $250 \mathrm{mM}$ $\mathrm{NaCl}$. Thus, in transgenic plants, young and old leaves exhibited significant lowest $\mathrm{Na}^{+}$ion content compared to NT plants (Figure 13A). $\mathrm{Na}^{+}$accumulation in young NT leaves was two-fold higher than in those of AlTMP1 transgenic lines. In general, both transgenic lines exhibited two-fold higher concentrations of $\mathrm{Na}^{+}$in old leaves than in young leaves under stress conditions. Furthermore, under control condition, all leaves of transgenic lines and NT exhibited $\mathrm{K}^{+}$contents that were nearly equal. However, under salt stress condition, young leaves of transgenic lines accumulated more $\mathrm{K}^{+}$and $\mathrm{Ca}^{2+}$ than those of NT plants (Figure 13B,D). Consequently, the transgenic plants were able to maintain a relatively high $\mathrm{K}^{+} / \mathrm{Na}^{+}$ratio compared to NT plants (Figure $13 \mathrm{C}$ ).

No significant difference in electrolyte leakage (EL) (Figure 14A) and membrane stability index (MSI) (Figure 14B) was noticed between transgenic and NT plants grown under control conditions. However, under stress condition, transgenic lines showed significantly higher MSI and lower EL 
compared to control plants (Figure 14A,B). These results could explain the better capacity of transgenic lines to maintain higher osmotic adjustment and $\mathrm{K}^{+} / \mathrm{Na}^{+}$ratio.

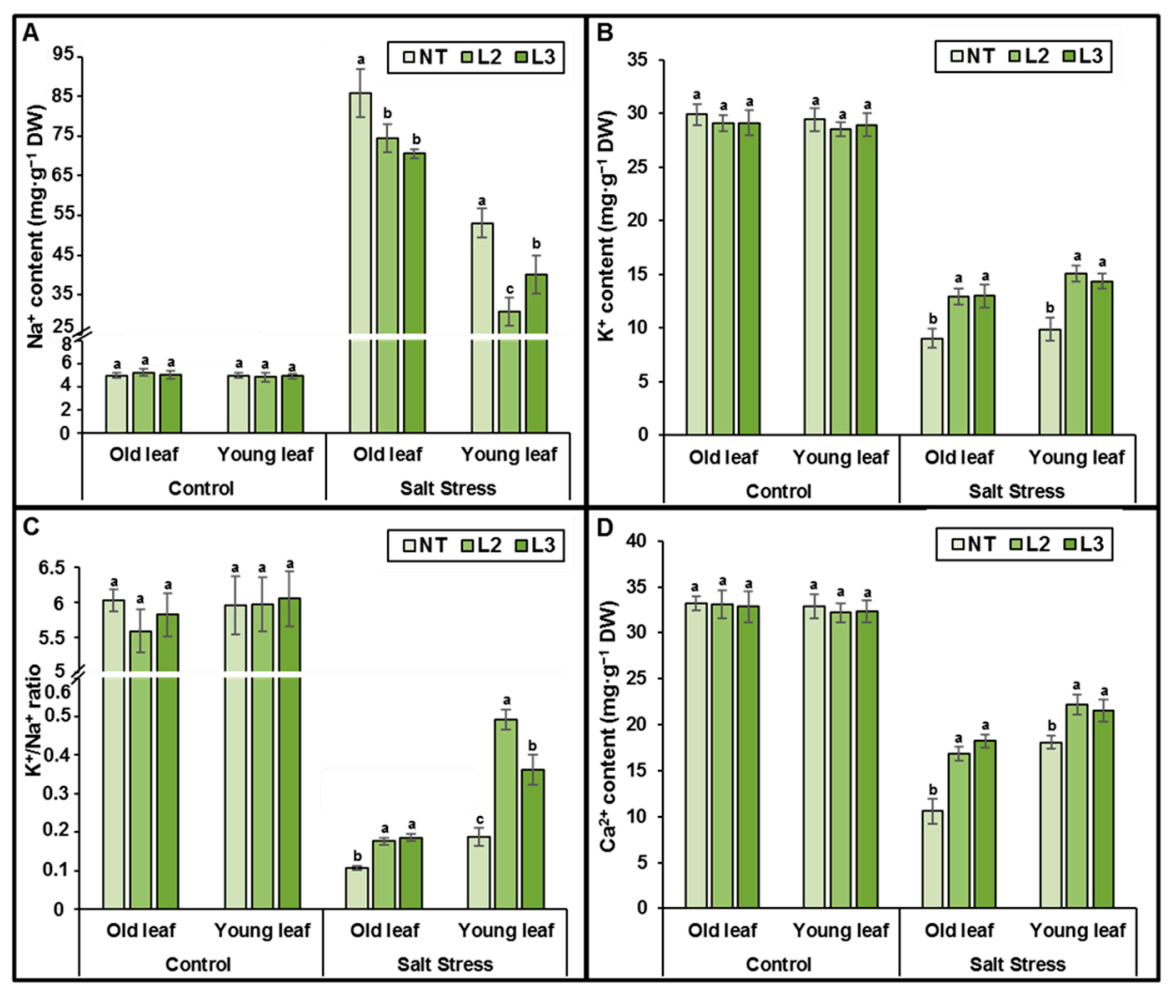

Figure 13. $\mathrm{Na}^{+}, \mathrm{K}^{+}$and $\mathrm{Ca}^{2+}$ contents in young and old leaves of non-transgenic and transgenic AlTMP1 (L2 and L3 lines) plants grown in a greenhouse under control and salt (250 $\mathrm{mM} \mathrm{NaCl})$ stress conditions. Values are mean \pm s.e. $(n=3)$. Means denoted by the same letter did not differ significantly at $p<0.05$.

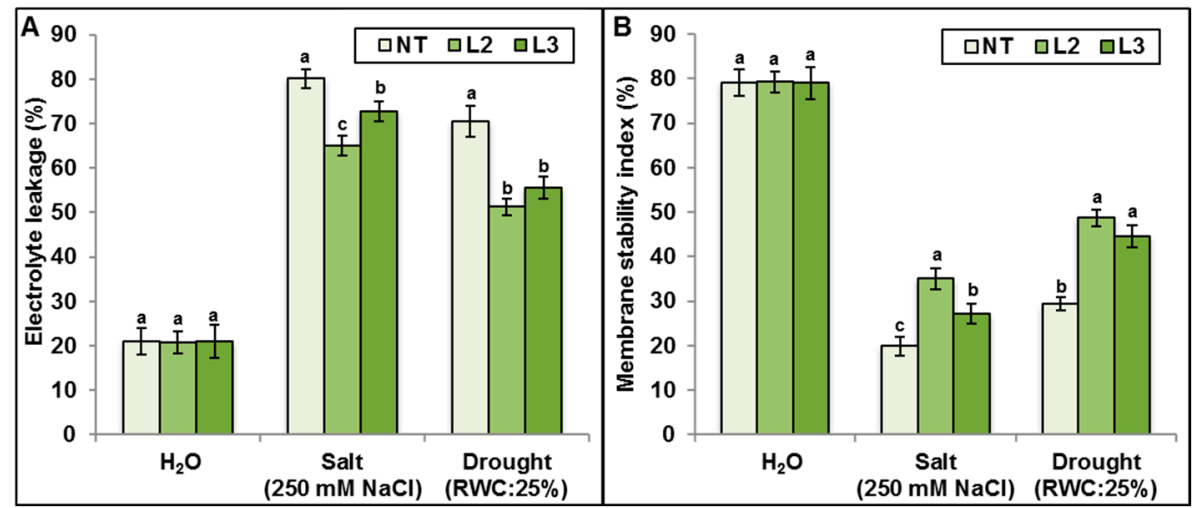

Figure 14. Electrolyte leakage (A); and membrane stability index (B) of non-transgenic and transgenic AlTMP1 (L2 and L3 lines) plants grown in greenhouse conditions under salt $(250 \mathrm{mM} \mathrm{NaCl})$ stress conditions. Values are mean \pm s.e. $(n=3)$. Means denoted by the same letter did not differ significantly at $p<0.05$.

\subsection{AlTMP1 Regulates the Expression of Some Stress-Related Genes in Transgenic Tobacco}

To further investigate the molecular mechanisms of enhanced abiotic stress tolerance afforded by the AlTMP1 expression, real-time qRT-PCR analysis was performed on eight stress-related genes in leaves of NT and transgenic tobacco plants grown under normal and stress conditions. As shown 
in Figure 15A, four (SOS2, DREB1A, APX1 and CAT1) and two (HKT1 and KT1) out of these eight genes were significantly $(p<0.05)$ up- and down-regulated, respectively, in transgenic AlTMP1 tobacco grown under control conditions. Under salt stress conditions, NHX1, DREB1A, APX1 and CAT 1 were significantly up-regulated while KT1 and HKT1 were down-regulated (Figure 15B). These results suggest that AlTMP1 possibly acts as a positive or negative regulator of genes involved in ions homeostasis (NHX1, SOS2, HKT1, KT1) and antioxidant defense system (CAT1, APX1) that contributes to the enhanced salt tolerance observed in transgenic AlTMP1 lines. Along the same line, accumulation of AlTMP1 resulted in the up-regulation of a key transcription factor, DREB1A responsible for the induction of multiple stress tolerance genes involved in drought, high salt, and cold responses.

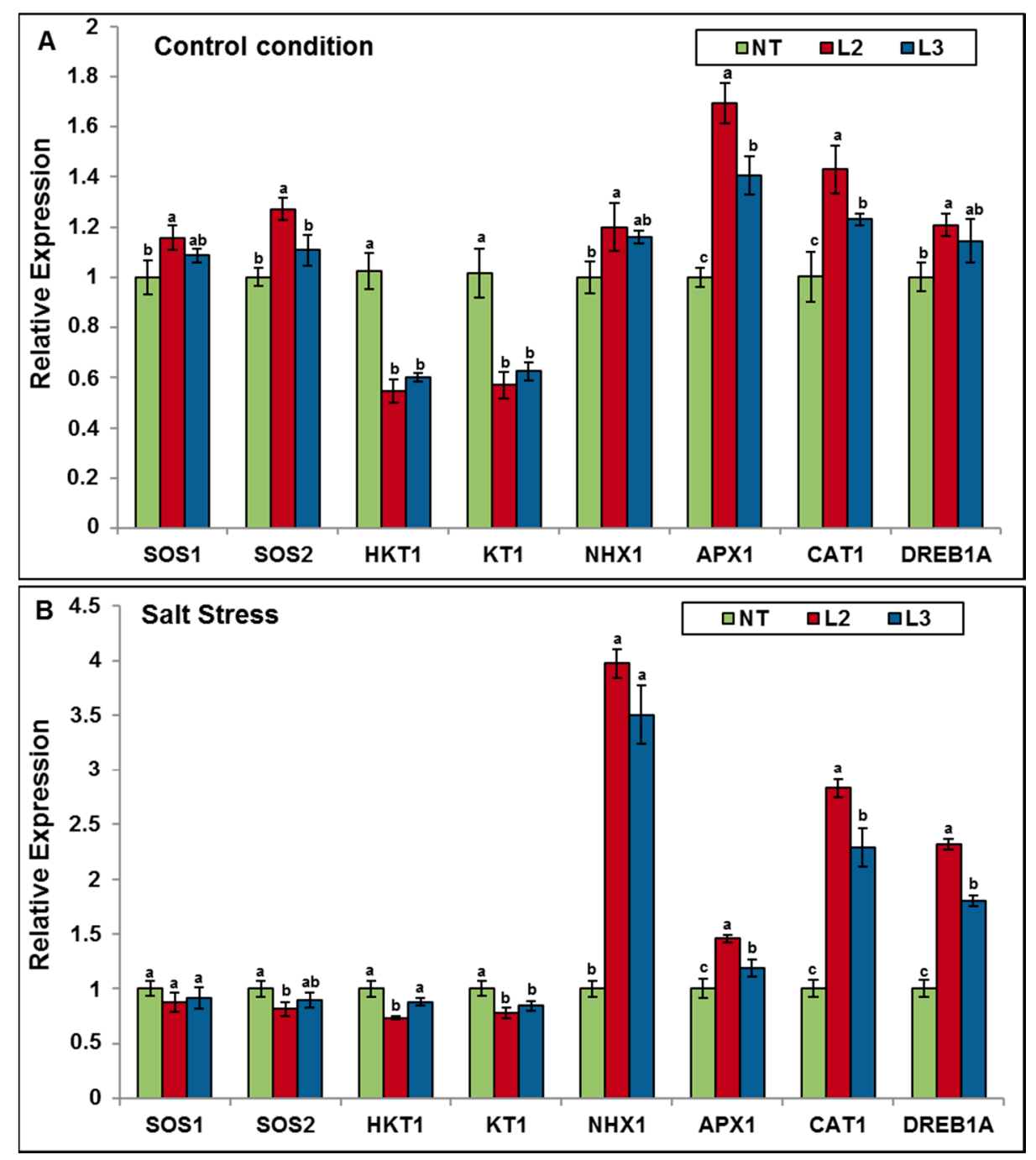

Figure 15. Relative expression of stress-related genes in AlTMP1 transgenic lines (L2, and L3) and NT tobacco plants under control and salt stress conditions. Values are mean \pm s.e. $(n=3)$. Means denoted by the same letter did not differ significantly at $p<0.05$.

\section{Discussion}

Plants are known to maintain their ion homeostasis in response to salt stress by increasing the concentration of $\mathrm{K}^{+}$in the cytosol with a concomitant decrease of $\mathrm{Na}^{+}$ions. These mechanisms are achieved by different classes of membrane proteins such as ion pumps, transporters, and channels [40]. Besides these genes, it was reported during the last decade that plants have protein homologs to the yeast plasma membrane protein 3 (PMP3) [41]. Numerous genes belonging to the PMP3 family have 
been isolated and characterized in several plants, including Arabidopsis, rice, wheat, barley, maize, sheep-grass, alkali-grass, and plantain $[3,13,23,37,38,42]$. These reports indicated that plant PMP3s might have a conserved function since the heterologous expression of some of them can functionally complement yeast pmp3 mutants by restoring the plasma membrane potential as well as the ion homeostasis $[3,41]$. We reported here the first isolation of a TMP1 gene from the C4 halophyte grass A. littoralis (AlTMP1) and established its role in conferring abiotic stress tolerance. The predicted AlTMP1 protein belongs to the yeast plasma membrane proteins 3 (PMP3) and has two homologs sharing $87.7 \%$ and $86.4 \%$ amino acid identity with rice OsLTI6b and maize ZmPMP3.1, respectively. The isolated gene AlTMP1 is induced by low temperature, salt stress, exogenous ABA, and osmotic stress. The rapid accumulation of AlTMP1 transcripts suggests that this gene is involved in the early response mechanisms to abiotic stresses. These results are in the same line with reports in other plants showing that the expression of PMP3 homologs is also up-regulated by different abiotic stress stimuli $[3,18,20]$. In A. littoralis, AlTMP1 was induced very early following cold, salt, ABA, and PEG treatments. A similar response was reported for PutPMP3.1/2, which are induced by different stresses, especially low temperature, salinity, and dehydration [23]. ESI3 from wheatgrass is induced by $\mathrm{NaCl}$, osmotic stress, and ABA treatments [37]. Similarly, it has been shown that the expression of AcPMP3.1 and AcPMP3.2 in sheep grass is induced in response to $\mathrm{ABA}, \mathrm{H}_{2} \mathrm{O}_{2}, \mathrm{SA}$, cold, salt and drought treatments [20]. Furthermore, it is known that plants can adjust abscisic acid (ABA) levels constantly in response to abiotic stresses, which in turn causes stomatal closure and induces expression of stress-related genes [43]. In this study, we showed that AlTMP1 is regulated by ABA, suggesting that it may be involved in the ABA-dependent signaling pathway. The AlTMP1 gene is induced by extracellular ABA treatment, whereas its nearest homolog gene ZmPMP3.1 (86.4\%) from maize is not [3]. Moreover, AlTMP1 is highly induced by osmotic stress, while ZmPMP3.1 is weakly induced by drought. In the same way for the second nearest homolog gene OsLTI6b (87.7\%) it was shown that its transcripts accumulated very quickly in leaves after one hour of ABA or dehydration treatments then dropped to almost a basal level. These results indicate that the three genes have different expression patterns in response to ABA and drought treatments despite their high identity. This may be ascribed to differences in regulatory sequences and may reflect the fact that $A$. littoralis is a halophyte whereas maize and rice are glycophytes.

Similar to plant PMP3 homologs, AlTMP1 protein has two putative hydrophobic transmembrane domains, localizing it to the plasma membrane and separated by a predicted short loop, which orientates both the $\mathrm{N}$ - and C-termini towards the apoplast. In addition, the subcellular localization assay of the GFP::AlTMP1 fusion confirmed a plasma membrane localization of AlTMP1. Similar results were also previously observed in wheat [17], maize [3], Arabidopsis [41], alkali grass P. tenuiflora [23] and A. chinense [20]. The association of PMP3 proteins with the plasma membrane corresponds to an expected role of PMP3s in regulating intracellular cation accumulation.

Accumulation of AlTMP1 transcripts in transgenic tobacco conferred tolerance to $\mathrm{NaCl}$, ionic, osmotic, cold and heat stresses under in vitro conditions. Furthermore, AlTMP1 homozygous transgenic lines were able to grow until maturity stage, to set flowers and to produce seeds when grown in the greenhouse under continuous salt and drought stresses. Under similar growth conditions, NT plants exhibited a stunted phenotype. Both in vitro and greenhouse assays revealed that protection afforded by AlTMP1 expression was more important for osmotic stress than for salt stress. Contrastingly, OsLti6b over-expressing rice plants exhibited no significant difference over non-transgenic controls under either salt or drought stress [27]. Accumulation of ZmPMP3.1 in Arabidopsis conferred salt stress tolerance, but these transgenic plants were not evaluated for drought stress tolerance [3]. The enhanced tolerance observed in transgenic AlTMP1 plants could be related to the low and high levels of accumulation in young tissues of $\mathrm{Na}^{+}$and $\mathrm{K}^{+}$, respectively. The adverse effect of salinity on plant growth and yield is known to be alleviated when $\mathrm{K}^{+}$and $\mathrm{Ca}^{2+}$ accumulate at a high level in plant tissues [44] thereby protecting young leaves from $\mathrm{Na}^{+}$ion toxicity. This could explain the relative normal growth of AlTMP1 plants and their ability to set and produce seeds under 
salt stress. In addition, the RWC of leaves was more important in AlTMP1 plants than in NT under stress most probably due to an improvement in membrane stability. Indeed, the AlTMP1 transgenic lines showed significantly higher MSI and considerably reduced electrolyte leakage under stress conditions compared to NT plants. These results were consolidated by the observation of a higher level of transcript accumulation of some stress-related genes (NHX1, CAT1, APX1 and DREB1A) in the transgenic plants than in the NT. Taken together, these results can suggest that expression of AlTMP1 can indirectly activate some stress-related genes leading to the observed tolerance to salt and drought stresses. Indeed, the up-regulation of CAT1 and APX1 genes in AlTMP1 transgenic lines under both control and stress conditions could increase the capacity of the plant to alleviate the reactive oxygen species (ROS) produced by the plant facing salinity or drought. HKT1 and KT1 genes were down-regulated in transgenic plants. Since KT and HKT-type proteins are probable candidates promoting $\mathrm{Na}^{+}$uptake into the root [45], their down-regulation could explain the lower $\mathrm{Na}^{+}$concentration in transgenic plant tissues. The vacuolar $\mathrm{Na}^{+} / \mathrm{H}^{+}$antiporter (NHX1) has long been proposed to play important roles in salt tolerance by the compartmentalization of $\mathrm{Na}^{+}$into the vacuole [46]. This mechanism reduces the deleterious effects of $\mathrm{Na}^{+}$excess in the cytosol and thus enhances water uptake and salt tolerance in plants by maintaining osmotic balance without spending much energy. DREB1A is reported to activate the transcription of more than 40 stress-inducible genes in Arabidopsis [47,48]. Based on these results, we propose that expression of AlTMP1 may up-regulate $D R E B 1 A$ which in turn induce some of its target stress genes in transgenic tobacco and thus result in enhanced stress tolerance.

\section{Materials and Methods}

\subsection{Plant Materials and AlTMP1 Gene Isolation}

A. littoralis and Nicotiana tabacum var. Xanthi was used in this study. Seeds of an A. littoralis were collected from salt marshes near "Sfax" a coastal town in the middle of Tunisia.

A full-length cDNA corresponding to AlTMP1 was isolated by screening an SSH cDNA library (cloned in pDNR-LIB vector, CLONTECH) previously prepared using RNA extracted from stressed A. littoralis roots during 15 days with $300 \mathrm{mM} \mathrm{NaCl}$ as described [31]. The differentially expressed full-length cDNA was sequenced by bidirectional sequencing with M13F and M13R primers (Table S1) and an ABI 3100 automatic DNA sequencer (Applied Biosystems, Foster City, CA, USA). The two sequenced fragments from $5^{\prime}$ and $3^{\prime}$, direction were assembled to generate the full-length cDNA "AlTMP1" sequence which was deposited in the Genbank with the accession number KY321744. The primers AlT1F5' and AlT1R3' (Table S1) were used to amplify the genomic clone of AlTMP1 gene. The generated fragment of $623 \mathrm{bp}$ was cloned into the pGEMT-easy vector (Promega, Madison, WI, USA), and three different positive clones were sequenced using SP6 and T7 universal primers.

The blastx and blastn were conducted by using the sequenced cDNA as a query to explore the homologs genes to AlTMP1 in NCBI GenBank (http://www.ncbi.nlm.nih.gov). The orthologues genes were used to perform multiple sequence alignments, and the degree of amino acid sequence identity was determined by the sequence editor software BioEdit 7.2.5. To predict the phylogenetic relationships between AlTMP1 and others PMP3 family proteins, we have used the MEGA6 software [49] to construct a phylogenetic tree. Various tools from Expasy (Expert Protein Analysis System, http://www.expasy.org/tools) were used to deduce the translated product and compute theoretical isoelectric point (pI) and molecular weight. The putative domains were identified by using the InterProscan search (http://www.ebi.ac.uk/interproscan). The prediction of the transmembrane helices of AlTMP1 putative protein was made via the THMM server v.2.0 (http://www.cbs.dtu.dk/services/TMHMM/). 


\subsection{Subcellular Localization of GFP::AlTMP1 Fusion Protein}

The AlTMP1 coding sequence was amplified by PCR using AlTMP1-B and AlTMP1-X primers containing Bam HI and $\mathrm{XbaI}$ restriction sites (Table S1). The amplified fragment was cloned into $\mathrm{BamHI} / \mathrm{XbaI}$ sites of the binary vector pCAMBIA2300-GFP to generate the fusion genes GFP::AlTMP1 driven by the CaMV-35S promoter. Both constructs pCAMBIA2300-GFP::AlTMP1 and pCAMBIA2300-GFP (as a control) were separately bombarded into a single layer of onion epidermal cells using the PDS-1000/He (Bio-Rad, Hercules, CA, USA) according to the manufacturer's protocol [50]. After incubation on MS medium for $36 \mathrm{~h}$ at $28{ }^{\circ} \mathrm{C}$ in darkness, the GFP signal was monitored, and the microscope imaging was performed at Montpellier RIO Imaging Platform (http:/ / www/mri/cnrs.fr) using a confocal microscope (LSM 510, Meta; Carl Zeiss MicroImaging, http://www.zeiss.de).

\subsection{Q-PCR Analysis of AlTMP1 and Stress-Related Genes}

Surface sterilized seeds of $A$. littoralis (1\% sodium hypochlorite solution for $15 \mathrm{~min}$, followed by washing six times with autoclaved distilled water, were germinated in Eppendorf tubes (Eppendorf, Hamburg, Germany) containing $500 \mu \mathrm{L}$ half strength MS (Murashige and Skoog medium) [51] solid medium and grown as described by [31]. After two months of growth, plants were treated with different stress factors: high salinity $(300 \mathrm{mM} \mathrm{NaCl})$, high osmotic pressure (20\% PEG 8000), low temperature $\left(4^{\circ} \mathrm{C}\right)$ and hormonal stress (100 $\mu \mathrm{M}$ abscisic acid (ABA)). Leaves from stressed plants were sampled at 0, 2, 4, 6, 24 and $48 \mathrm{~h}$ after each treatment and immediately frozen in liquid nitrogen and stored at $-80^{\circ} \mathrm{C}$ for RNA extraction and real-time quantitative RT-PCR (qRT-PCR) analysis of AlTMP1 gene.

Total RNA was extracted from either A. littoralis or tobacco leaves using the RNAeasy Plant Mini kit (Qiagen, Hilden, Germany) according to the manufacturer's protocol. The RNA was treated with DNaseI (RQ1 kit, Promega) at $37^{\circ} \mathrm{C}$ for $15 \mathrm{~min}$ to remove the remaining genomic DNA. Synthesis of the first-strand cDNA was performed using $5 \mu \mathrm{g}$ treated total RNA, SuperScript ${ }^{\mathrm{TM}}$ III reverse transcriptase (Invitrogen, Carlsbad, CA, USA), oligo- $\left(\mathrm{dT}_{18}\right)$ and random hexamer primers according to manufacturer's instruction.

Quantitative real-time RT-PCR (qRT-PCR) was used for analyzing expression patterns of AlTMP1 under various stress treatments in $A$. littoralis using qAlT1-F and qAlT1-R primers (Table S1). In addition, the transcript accumulation was monitored by real-time qPCR for eight stress-related genes (Table S1) in T2 homozygous transgenic lines and NT tobacco plants sampled under both control and stress conditions. The cDNAs prepared as described above from A. littoralis or transgenic tobacco lines were used in real-time qPCR reactions. The qPCR reactions were carried out using the LightCycler480 System and the LightCycler ${ }^{\circledR} 480$ SYBR Green I Master (Roche, Mannheim, Germany) according to the supplier's manuals. The PCR cycling conditions were as follows: $95{ }^{\circ} \mathrm{C}$ for $3 \mathrm{~min}$, followed by 40 cycles of $95{ }^{\circ} \mathrm{C}$ for $20 \mathrm{~s}$ and $60{ }^{\circ} \mathrm{C}$ for $30 \mathrm{~s}$ and $72{ }^{\circ} \mathrm{C}$ for $1 \mathrm{~min}$. A melting curve was routinely performed after 40 cycles to verify primer specificity. Fragments of $18 \mathrm{~S}$ rRNA gene ( $600 \mathrm{pb}, 18 \mathrm{SF}$ and $18 \mathrm{SR})$ and actin gene ( $380 \mathrm{bp}$, ACT-F and ACT-R) were used as an internal reference for $A$. littoralis and tobacco plants respectively (Table S1). The stress related genes monitored in transgenic tobacco encode $\mathrm{Na}^{+}$transporter (HKT1, AB061311) [52], $\mathrm{K}^{+}$transmembrane transporter (KT1, NM001336238.1) [53], $\mathrm{Na}^{+} / \mathrm{H}^{+}$antiporter (SOS1, AY785147) [54], $\mathrm{Na}^{+} / \mathrm{H}^{+}$exchanger 1 (NHX1, JX987081.1) [28], serine/threonine protein kinase (SOS2, NM_122932.5) [55], DRE-binding proteins (DREB1A, AF300970) [56], catalase1 (CAT1, U93244.1) [57] and ascorbate peroxidase (APX1, AK061841). All primers were designed by Primer3Plus (http://primer3plus.com/cgi-bin/dev/primer3plus.cgi) [58]. The quantitative analysis was performed using the $\Delta \Delta C_{\mathrm{T}}$ comparative method (2- $2^{-\Delta \Delta \mathrm{Ct}}$ method, in which $C_{\mathrm{T}}$ indicates cycle threshold) [59]. Statistical analysis was performed on $\Delta \Delta C_{\mathrm{t}}$. For the analysis of AlTMP1 expression under various treatments, $\Delta \Delta C_{\mathrm{t}}=\left(C_{\mathrm{t}}\right.$ AlTMP1 $\left.-C_{\mathrm{t} 18 \mathrm{~s}}\right)$ Time $x-\left(C_{\mathrm{t}}\right.$ AlTMP1 $\left.-C_{\mathrm{t} 18 \mathrm{~s}}\right)$ Time 0 . Time $x$ is any treated time point $(2,4,6,24$ and $48 \mathrm{~h})$, and Time 0 represents the untreated 
time $(0 \mathrm{~h})$. For the analysis of stress-related genes expression in transgenic lines and NT, $\Delta \Delta C_{t}=\left(C_{t} \text { target gene }-C_{t} \text { actin }\right)_{\text {transgenic line }}-\left(C_{t} \text { target gene }-C_{t} \text { actin }\right)_{N T}$. Relative expression ratios are reported from three independent experiments (three biological repetitions).

For semi-quantitative RT-PCR Polymerase master mix (Kapa Biosystems, Woburn, MA, USA) was used. $10 \mu \mathrm{L}$ of the PCR product was separated on a $1 \%$ agarose gel to visualize the intensity of gene amplification. As an internal control, the primers ACT-F and ACT-R (Table S1) were used to amplify a fragment of actin gene ( $380 \mathrm{bp}$ ) as a control for equal cDNA loading. The experiment was repeated three times to ensure reproducibility.

\subsection{Generation of Transgenic Tobacco Expressing AlTMP1}

The plasmid pDNR-LIB was digested with XbaI and SmaI to release the cDNA fragment of AlTMP1 gene, which was purified from the gel and finally cloned in the binary vector pCAMBIA1390 (CAMBIA, Canberra, Australia) under the control of the CaMV35S promoter and Nos-polyA terminator. The resulting pCAMBIA1390-AlTMP1 construct was then mobilized into Agrobacterium tumefaciens strain EHA105 [60] by electroporation method [61]. Agrobacterium-mediated leaf disc transformation of tobacco was carried out per standard protocol [62]. Transgenic T0 plants were grown to maturity after selection on MS agar medium containing $50 \mathrm{mg} / \mathrm{L}$ Hygromycin B (Sigma-Aldrich, St. Louis, MO, USA). T1 seeds were again germinated on MS agar medium with Hygromycin B, and the resistant transgenic lines were grown to obtain the T2 homozygous lines used for further analysis. The presence and expression of AlTMP1 were ascertained by PCR and RT-PCR analysis, respectively.

\subsection{Evaluation of Transgenic Tobacco Tolerance to Abiotic Stresses}

The AlTMP1 transgenic tobacco plants (L2 and L3) of homozygous T2 generation were used in the subsequent abiotic stress assays. Seeds of non-transgenic (NT) and transgenic plants were surface sterilized and plated on MS0, MSOm (MS0 with $350 \mathrm{mM}$ mannitol) and MS0s (MS0 with $200 \mathrm{mM} \mathrm{NaCl}$ ). The plates (three replicates of 100 seeds) were placed in a growth chamber under a $16 \mathrm{~h} \mathrm{light} / 8 \mathrm{~h}$ dark cycle at $25{ }^{\circ} \mathrm{C}$. The number of germinated seeds was scored every two days for three weeks. Germination was defined as a clear emergence of the radicle through the seed coat. To survey the effects of salt and osmotic stresses on root elongation of NT and T2 (L2 and L3) transgenic AlTMP1 lines. The seeds were germinated in MS medium supplemented with 0, 100, 150 and $200 \mathrm{mM} \mathrm{NaCl}$ or 200, 300 and $400 \mathrm{mM}$ Mannitol and grown for one month. Root length, for both transgenic and NT seedlings, were determined after four weeks of growth.

To evaluate the effect of osmotic (400 mM Mannitol), salt (200 mM NaCl) and ionic (100 $\mathrm{mM} \mathrm{LiCl})$ stresses on shoot elongation, and RWC of leaves under in vitro culture conditions, transgenic and NT seedlings were transferred to stressing media after ten days of germination on MS0. The shoot length, number of leaves and dry weight was monitored following one month of growth.

Chlorophyll content was estimated using 10 leaf discs from non-transgenic and transgenic plants (one $\mathrm{cm}$ leaf disc) per treatment. These discs were floated on MS liquid medium containing 0 , $700 \mathrm{mM} \mathrm{NaCl}, 400 \mathrm{mM} \mathrm{LiCl}, 300 \mathrm{mM} \mathrm{H} \mathrm{O}_{2}$ or 20\% PEG for $72 \mathrm{~h}$. The total chlorophyll content in each sample was calculated after extraction in aqueous $80 \%$ acetone using the following formulae [63] which express [Chl a], [Chl b] and [Chls a $+\mathrm{b}]$ in $\mu \mathrm{g} \cdot \mathrm{mL}^{-1}$ : [Chl a] $=12.70 \times A_{663}-2.69 \times A_{645}$, $[\mathrm{Chl} \mathrm{b}]=22.90 \times A_{645}-4.68 \times A_{663},[$ Chls $\mathrm{a}+\mathrm{b}]=20.21 \times A_{645}+8.02 \times A_{663}$. The $A_{663}$ and $A_{645}$ represent absorbance values read at $663 \mathrm{~nm}$ and $645 \mathrm{~nm}$ wavelengths, respectively.

For freezing and heat stresses, one-month-old seedlings of transgenic and NT plants grown in peat under greenhouse conditions were incubated at -20 or $55^{\circ} \mathrm{C}$ for two hours. Plant survival and dry weights were determined after five days recovery in the greenhouse.

To monitor the drought and salt effects under greenhouse conditions, seeds of homozygous transgenic lines (L2 and L3) and NT plants were germinated and grown on MS medium supplemented with $50 \mathrm{mg} / \mathrm{L}$ hygromycin for one month. The seedlings were then transferred to pots filled with 
a 3:1 mixture of soil and peat and grown in a greenhouse for more two weeks before being exposed to stress treatments. For normal growth conditions transgenic and NT plants were irrigated with water to maintain the RWC of soil at $75 \%$. For salt stress treatment, the same irrigation program was used with the addition of $250 \mathrm{mM} \mathrm{NaCl}$ to water until the end of plant cycle. This $\mathrm{NaCl}$ concentration was increased gradually from 150 to $250 \mathrm{mM}$ within the first 15 days of stress treatment. For drought stress, the RWC of the soil was maintained at $25 \%$. For all treatments, leaf RWC, plant height, dry weight of roots and shoots, and seed yield were determined.

\subsection{Ion Content Determination}

The accumulation of $\mathrm{Na}^{+}, \mathrm{K}^{+}$and $\mathrm{Ca}^{2+}$ concentrations in young and old leaves was determined for plants grown at $250 \mathrm{mM} \mathrm{NaCl}$. Leaves were collected from salt-stressed treated plants and then washed thoroughly with distilled water, then dried at $80{ }^{\circ} \mathrm{C}$ until constant weight was reached. The dried leaves were incubated for one week with $0.5 \% \mathrm{HNO}_{3}$. The filtrate from each sample was analyzed by atomic absorption spectrometer (Thermo Scientific ${ }^{\mathrm{TM}}$, Loughborough, UK). Concentrations were calculated as $\mathrm{mg} \cdot \mathrm{g}^{-1}$ dry weight. The $\mathrm{K}^{+} / \mathrm{Na}^{+}$ratio was also determined.

\subsection{Membrane Stability Index and Electrolyte Leakage Assay}

Membrane stability index (MSI) was measured as described by [64]. Two sets of leaf samples were taken in $10 \mathrm{~mL}$ of double-distilled water. One set was heated at $40^{\circ} \mathrm{C}$ for $30 \mathrm{~min}$ in a water bath, and its conductivity (C1) was recorded using Oakton PC2700 conductivity meter (Oakton Instruments, USA). The second set was boiled at $100{ }^{\circ} \mathrm{C}$ for $10 \mathrm{~min}$ before having its conductivity (C2) measured. MSI was calculated using the following formula: MSI $=[1-(C 1 / C 2)] \times 100$.

Electrolyte leakage was measured as described by [65]. The third leaf from the top, with similar size, was collected from three plants for each line and each treatment and washed thoroughly with deionized water to remove electrolytes adhered on the surface. The samples were placed in closed vials containing $10 \mathrm{~mL}$ of deionized water, incubated at $25^{\circ} \mathrm{C}$ on a rotary shaker for $24 \mathrm{~h}$, and the electrical conductivity of the solution (EC1) was determined using an Oakton PC2700 conductivity meter (Oakton Instruments, Vernon Hills, IL, USA). The samples were then autoclaved at $120^{\circ} \mathrm{C}$ for $20 \mathrm{~min}$, and the final electrical conductivity (EC2) was obtained after cooling at $25^{\circ} \mathrm{C}$. The electrolyte leakage was defined as follows: Electrolyte leakage $(\%)=(E C 1 / E C 2) \times 100$.

\subsection{Statistical Analyses}

The data for all experiments have been calculated from three replications, and different values have been presented as mean \pm s.e. (standard error). Statistical analyses were carried out using xISTAT, and one-way ANOVA [66] followed by Bonferroni's post hoc test was used to assess if the variations between treatments are statistically significant. Mean values that were significantly different at $p<0.05$ from each other are marked with different lowercase letters inside the figures.

\section{Conclusions}

In the present study, an AlTMP1 gene was isolated from the halophyte C4 grass A. littoralis. This gene encodes a transmembrane polypeptide of 57 amino acids belonging to the family of plasma membrane protein 3 (PMP3) and has two nearest homologs in rice (OsLTI6b) and maize (ZmPMP3.1). This study is the first demonstration that a member of the PMP3 family confers stress tolerance and enhances seed yield in transgenic AlTMP1 lines subjected to continuous drought and salinity treatments in the greenhouse. Noteworthy, this gene confers higher tolerance to drought than to salt stress. Finally, the expression of AlTMP1 resulted in the deregulation of some stress related tobacco genes. Further study using RNAseq analysis of transgenic plants expressing AlTMP1 will contribute to our understanding of the mechanisms behind the stress-tolerance observed in these plants.

Supplementary Materials: Supplementary materials can be found at www.mdpi.com/1422-0067/18/4/692/s1. 
Acknowledgments: All sources of funding of the study are from The National Plan for Science Technology and Innovation, http://npst.ksu.edu.sa/en (NPSTI, Project No. 11-Bio1828-02) in the Kingdom of Saudi Arabia. The funders had no role in study design, data collection, and analysis, decision to publish, or preparation of the manuscript. The authors are grateful to the Deanship of Scientific Research, King Saud University, and Agricultural Research Center, College of Food and Agriculture Sciences. The authors thank the Visiting Professor Program of King Saud University Saudi Arabia and the Agropolis Foundation under the REFUGE platform, CIRAD-Montpellier France for encouraging this collaborative work.

Author Contributions: Afif Hassairi, Walid Ben Romdhane and Emmanuel Guiderdoni conceived and designed the experiments. Walid Ben Romdhane, Afif Hassairi, Rania Ben-Saad, Donaldo Meynard, Jalel Azaza and Jean-Luc Verdeil conducted experiments. Walid Ben Romdhane and Afif Hassairi analyzed the data. Nabil Zouari, Abdullah Al-Doss, and Lotfi Fki contributed reagents/materials/analysis tools and reviewed the paper. Afif Hassairi, Walid Ben Romdhane and Emmanuel Guiderdoni wrote the paper. All authors read and approved the manuscript.

Conflicts of Interest: The authors declare no conflict of interest.

\section{References}

1. Acquaah, G. Principles of Plant Genetics and Breeding; John Wiley \& Sons: Hoboken, NJ, USA, 2009.

2. Gupta, B.A.O.; Huang, B. Mechanism of salinity tolerance in plants: Physiological, biochemical, and molecular characterization. Int. J. Genom. 2014, 2014, 701596. [CrossRef] [PubMed]

3. Fu, J.; Zhang, D.F.; Liu, Y.H.; Ying, S.; Shi, Y.S.; Song, Y.C.; Li, Y.; Wang, T.Y. Isolation and characterization of maize PMP3 genes involved in salt stress tolerance. PLoS ONE 2012, 7, e31101. [CrossRef] [PubMed]

4. Flowers, T.J.; Colmer, T.D. Salinity tolerance in halophytes. New Phytol. 2008, 179, 945-963. [CrossRef] [PubMed]

5. Flowers, T.J.; Munns, R.; Colmer, T.D. Sodium chloride toxicity and the cellular basis of salt tolerance in halophytes. Ann. Bot. 2015, 115, 419-431. [CrossRef] [PubMed]

6. Volkov, V. Salinity tolerance in plants. Quantitative approach to ion transport starting from halophytes and stepping to genetic and protein engineering for manipulating ion fluxes. Front. Plant Sci. 2015, 6, 873. [CrossRef] [PubMed]

7. Bassil, E.; Coku, A.; Blumwald, E. Cellular ion homeostasis: Emerging roles of intracellular $\mathrm{NHX} \mathrm{Na}^{+} / \mathrm{H}^{+}$ antiporters in plant growth and development. J. Exp. Bot. 2012, 63, 5727-5740. [CrossRef] [PubMed]

8. Gassmann, W.; Rubio, F.; Schroeder, J.I. Alkali cation selectivity of the wheat root high-affinity potassium transporter HKT1. Plant J. 1996, 10, 869-882. [CrossRef]

9. Uozumi, N.; Kim, E.J.; Rubio, F.; Yamaguchi, T.; Muto, S.; Tsuboi, A.; Bakker, E.P.; Nakamura, T.; Schroeder, J.I. The Arabidopsis HKT1 gene homolog mediates inward $\mathrm{Na}^{+}$currents in Xenopus laevis oocytes and $\mathrm{Na}^{+}$uptake in Saccharomyces cerevisiae. Plant Physiol. 2000, 122, 1249-1260. [CrossRef] [PubMed]

10. Demidchik, V.; Tester, M. Sodium fluxes through nonselective cation channels in the plasma membrane of protoplasts from Arabidopsis roots. Plant Physiol. 2002, 128, 379-387. [CrossRef] [PubMed]

11. Guo, K.M.; Babourina, O.; Christopher, D.A.; Borsic, T.; Rengel, Z. The cyclic nucleotide-gated channel AtCNGC10 transports $\mathrm{Ca}^{2+}$ and $\mathrm{Mg}^{2+}$ in Arabidopsis. Physiol. Plant. 2010, 139, 303-312. [PubMed]

12. Navarre, C.; Goffeau, A. Membrane hyperpolarization and salt sensitivity induced by deletion of PMP3, a highly conserved small protein of yeast plasma membrane. EMBO J. 2000, 19, 2515-2524. [CrossRef] [PubMed]

13. Nylander, M.; Heino, P.; Helenius, E.; Palva, E.T.; Ronne, H.; Welin, B.V. The low-temperature- and salt-induced RCI2A gene of Arabidopsis complements the sodium sensitivity caused by a deletion of the homologous yeast gene SNA1. Plant Mol. Biol. 2001, 45, 341-352. [CrossRef] [PubMed]

14. Wang, L.Y.; Shiozaki, K. The fission yeast stress MAPK cascade regulates the pmp3 ${ }^{+}$gene that encodes a highly conserved plasma membrane protein. FEBS Lett. 2006, 580, 2409-2413. [CrossRef] [PubMed]

15. Goddard, N.J.; Dunn, M.A.; Zhang, L.; White, A.J.; Jack, P.L.; Hughes, M.A. Molecular analysis and spatial expression pattern of a low-temperature-specific barley gene, Blt101. Plant Mol. Biol. 1993, 23, 871-879. [CrossRef] [PubMed]

16. Morsy, M.R.; Almutairi, A.M.; Gibbons, J.; Yun, S.J.; de los Reyes, B.G. The OsLti6 genes encoding low-molecular-weight membrane proteins are differentially expressed in rice cultivars with contrasting sensitivity to low temperature. Gene 2005, 344, 171-180. [CrossRef] [PubMed] 
17. Imai, R.; Koike, M.; Sutoh, K.; Kawakami, A.; Torada, A.; Oono, K. Molecular characterization of a cold-induced plasma membrane protein gene from wheat. Mol. Genet. Genom. 2005, 274, 445-453. [CrossRef] [PubMed]

18. Wang, D.H.; Chen, Y.Q.; Wang, Y.; Wang, Z.Z. Molecular cloning and expression of two plasma membrane protein 3 (SmPMP3) genes from Salvia miltiorrhiza. Russ. J. Plant Physiol. 2013, 60, 155-164. [CrossRef]

19. Medina, J.; Catala, R.; Salinas, J. Developmental and stress regulation of RCI2A and RCI2B, two cold-inducible genes of arabidopsis encoding highly conserved hydrophobic proteins. Plant Physiol. 2001, 125, 1655-1666. [CrossRef] [PubMed]

20. Inada, M.; Ueda, A.; Shi, W.M.; Takabe, T. A stress-inducible plasma membrane protein 3 (AcPMP3) in a monocotyledonous halophyte, Aneurolepidium chinense, regulates cellular $\mathrm{Na}^{+}$and $\mathrm{K}^{+}$accumulation under salt stress. Planta 2005, 220, 395-402. [CrossRef] [PubMed]

21. Rocha, P.S.C.F. Plant abiotic stress-related RCI2/PMP3s: Multigenes for multiple roles. Planta 2015, $243,1-12$. [CrossRef] [PubMed]

22. Long, R.C.; Zhang, F.; Li, Z.Y.; Li, M.N.; Cong, L.L.; Kang, J.M.; Zhang, T.J.; Zhao, Z.X.; Sun, Y.; Yang, Q.C. Isolation and functional characterization of salt-stress induced RCI2-like genes from Medicago sativa and Medicago truncatula. J. Plant Res. 2015, 128, 697-707. [CrossRef] [PubMed]

23. Chang-Qing, Z.; Shunsaku, N.; Shenkui, L.; Tetsuo, T. Characterization of two plasma membrane protein 3 genes (PutPMP3) from the alkali grass, Puccinellia tenuiflora, and functional comparison of the rice homologues, OsLti6a/b from rice. BMB Rep. 2008, 41, 448-454. [CrossRef] [PubMed]

24. Mitsuya, S.; Taniguchi, M.; Miyake, H.; Takabe, T. Disruption of RCI2A leads to over-accumulation of Na+ and increased salt sensitivity in Arabidopsis thaliana plants. Planta 2005, 222, 1001-1009. [CrossRef] [PubMed]

25. Mitsuya, S.; Taniguchi, M.; Miyake, H.; Takabe, T. Overexpression of $R C I 2 A$ decreases $\mathrm{Na}^{+}$uptake and mitigates salinity-induced damages in Arabidopsis thaliana plants. Physiol. Plant. 2006, 128, 95-102. [CrossRef]

26. Liu, B.; Feng, D.R.; Zhang, B.P.; Mu, P.Q.; Zhang, Y.; He, Y.M.; Qi, K.B.; Wang, J.F.; Wang, H.B. Musa paradisica RCI complements AtRCI and confers $\mathrm{Na}^{+}$tolerance and $\mathrm{K}^{+}$sensitivity in Arabidopsis. Plant Sci. 2012, 184, 102-111. [CrossRef] [PubMed]

27. Kim, S.H.; Kim, J.Y.; Kim, S.J.; An, K.S.; An, G.; Kim, S.R. Isolation of cold stress-responsive genes in the reproductive organs, and characterization of the OsLti6b gene from rice (Oryza sativa L.). Plant Cell Rep. 2007, 26, 1097-1110. [CrossRef] [PubMed]

28. Chen, X.; Bao, H.; Guo, J.; Jia, W.; Tai, F.; Nie, L.; Jiang, P.; Feng, J.; Lv, S.; Li, Y. Na ${ }^{+} / \mathrm{H}^{+}$exchanger 1 participates in tobacco disease defence against Phytophthora parasitica var. nicotianae by affecting vacuolar pH and priming the antioxidative system. J. Exp. Bot. 2014, 65, 6107-6122. [CrossRef] [PubMed]

29. Osakabe, Y.; Watanabe, T.; Sugano, S.S.; Ueta, R.; Ishihara, R.; Shinozaki, K.; Osakabe, K. Optimization of CRISPR/Cas9 genome editing to modify abiotic stress responses in plants. Sci. Rep. 2016, 6, 26685. [CrossRef] [PubMed]

30. Lucas, S.; Dogan, E.; Budak, H. TMPIT1 from wild emmer wheat: First characterisation of a stress-inducible integral membrane protein. Gene 2011, 483, 22-28. [CrossRef] [PubMed]

31. Zouari, N.; Ben Saad, R.; Legavre, T.; Azaza, J.; Sabau, X.; Jaoua, M.; Masmoudi, K.; Hassairi, A. Identification and sequencing of ESTs from the halophyte grass Aeluropus littoralis. Gene 2007, 404, 61-69. [CrossRef] [PubMed]

32. Ben Saad, R.; Zouari, N.; Ben Ramdhan, W.; Azaza, J.; Meynard, D.; Guiderdoni, E.; Hassairi, A. Improved drought and salt stress tolerance in transgenic tobacco overexpressing a novel A20/AN1 zinc-finger "AlSAP" gene isolated from the halophyte grass Aeluropus littoralis. Plant Mol. Biol. 2010, 72, 171. [CrossRef] [PubMed]

33. Ben Saad, R.; Ben Romdhan, W.; Zouari, N.; Azaza, J.; Mieulet, D.; Verdeil, J.-L.; Guiderdoni, E.; Hassairi, A. Promoter of the AISAP gene from the halophyte grass Aeluropus littoralis directs developmental-regulated, stress-inducible, and organ-specific gene expression in transgenic tobacco. Transg. Res. 2011, 20, 1003-1018. [CrossRef] [PubMed]

34. Ben Saad, R.; Ben Ramdhan, W.; Zouari, N.; Azaza, J.; Mieulet, D.; Guiderdoni, E.; Ellouz, R.; Hassairi, A. Marker-free transgenic durum wheat cv. Karim expressing the AlSAP gene exhibits a high level of tolerance to salinity and dehydration stresses. Mol. Breed. 2012, 30, 521-533. [CrossRef]

35. Ben Saad, R.; Fabre, D.; Mieulet, D.; Meynard, D.; Dingkuhn, M.; Al-Doss, A.; Guiderdoni, E.; Hassairi, A. Expression of the Aeluropus littoralis AlSAP gene in rice confers broad tolerance to abiotic stresses through maintenance of photosynthesis. Plant Cell Environ. 2012, 35, 626-643. [CrossRef] [PubMed] 
36. Krogh, A.; Larsson, B.; von Heijne, G.; Sonnhammer, E.L.L. Predicting transmembrane protein topology with a hidden markov model: Application to complete genomes. J. Mol. Biol. 2001, 305, 567-580. [CrossRef] [PubMed]

37. Gulick, P.J.; Shen, W.; An, H. ESI3, a stress-induced gene from Lophopyrum elongatum. Plant Physiol. 1994, 104, 799-800. [CrossRef] [PubMed]

38. Feng, D.R.; Liu, B.; Li, W.Y.; He, Y.M.; Qi, K.B.; Wang, H.B.; Wang, J.F. Over-expression of a cold-induced plasma membrane protein gene $(\mathrm{MpRCI})$ from plantain enhances low temperature-resistance in transgenic tobacco. Environ. Exp. Bot. 2009, 65, 395-402. [CrossRef]

39. Capel, J.; Jarillo, J.A.; Salinas, J.; Martinez-Zapater, J.M. Two homologous low-temperature-inducible genes from Arabidopsis Encode highly hydrophobic proteins. Plant Physiol. 1997, 115, 569-576. [CrossRef] [PubMed]

40. Serrano, R.; Rodriguez, P.L. Plants, genes and ions: Workshop on the molecular basis of ionic homeostasis and salt tolerance in plants. EMBO Rep. 2002, 3, 116-119. [CrossRef] [PubMed]

41. Medina, J.; Ballesteros, M.L.; Salinas, J. Phylogenetic and functional analysis of Arabidopsis RCI2 genes. J. Exp. Bot. 2007, 58, 4333-4346. [CrossRef] [PubMed]

42. Galvez, A.F.; Gulick, P.J.; Dvorak, J. Characterization of the early stages of genetic salt-stress responses in salt-tolerant Lophopyrum elongatum, salt-sensitive wheat, and their Amphiploid. Plant Physiol. 1993, 103, 257-265. [CrossRef] [PubMed]

43. Tuteja, N. Abscisic acid and abiotic stress signaling. Plant Signal Behav. 2007, 2, 135-138. [CrossRef] [PubMed]

44. Giri, B.; Kapoor, R.; Mukerji, K.G. Improved tolerance of Acacia nilotica to salt stress by Arbuscular mycorrhiza, Glomus fasciculatum may be partly related to elevated K/Na ratios in root and shoot tissues. Microb. Ecol. 2007, 54, 753-760. [CrossRef] [PubMed]

45. Wang, Q.; Guan, C.; Wang, P.; Lv, M.L.; Ma, Q.; Wu, G.Q.; Bao, A.K.; Zhang, J.L.; Wang, S.M. AtHKT $1 ; 1$ and AtHAK $_{5}$ mediate low-affinity $\mathrm{Na}+$ uptake in Arabidopsis thaliana under mild salt stress. Plant Growth Regul. 2014, 75, 615-623. [CrossRef]

46. Bhaskaran, S.; Savithramma, D. Co-expression of Pennisetum glaucum vacuolar $\mathrm{Na}^{+} / \mathrm{H}^{+}$antiporter and Arabidopsis $\mathrm{H}^{+}$-pyrophosphatase enhances salt tolerance in transgenic tomato. J. Exp. Bot. 2011, 62, 5561-5570. [CrossRef] [PubMed]

47. Seki, M. Monitoring the expression pattern of 1300 Arabidopsis genes under drought and cold stresses by using a full-length cDNA microarray. Plant Cell Online 2001, 13, 61-72. [CrossRef]

48. Akpinar, B.A.; Avsar, B.; Lucas, S.J.; Budak, H. Plant abiotic stress signaling. Plant Signal Behav. 2012, 7 , 1450-1455. [CrossRef] [PubMed]

49. Tamura, K.; Stecher, G.; Peterson, D.; Filipski, A.; Kumar, S. MEGA6: Molecular evolutionary genetics analysis version 6.0. Mol. Biol. Evol. 2013, 30, 2725-2729. [CrossRef] [PubMed]

50. Nebenführ, A. Identifying subcellular protein localization with fluorescent protein fusions after transient expression in onion epidermal cells. Methods Mol. Biol. 2014, 1080, 77-85. [PubMed]

51. Murashige, T.; Skoog, F. A revised medium for rapid growth and bio assays with tobacco tissue cultures. Physiol. Plant 1962, 15, 473-497. [CrossRef]

52. Horie, T.; Yoshida, K.; Nakayama, H.; Yamada, K.; Oiki, S.; Shinmyo, A. Two types of HKT transporters with different properties of $\mathrm{Na}^{+}$and $\mathrm{K}^{+}$transport in Oryza sativa. Plant J. 2001, 27, 129-138. [CrossRef] [PubMed]

53. Lin, X.; Kaul, S.; Rounsley, S.; Shea, T.P.; Benito, M.-I.; Town, C.D.; Fujii, C.Y.; Mason, T.; Bowman, C.L.; Barnstead, M.; et al. Sequence and analysis of chromosome 2 of the plant Arabidopsis thaliana. Nature 1999, 402, 761-768. [CrossRef] [PubMed]

54. Martinez-Atienza, J.; Jiang, X.; Garciadeblas, B.; Mendoza, I.; Zhu, J.K.; Pardo, J.M.; Quintero, F.J. Conservation of the salt overly sensitive pathway in rice. Plant Physiol. 2006, 143, 1001-1012. [CrossRef] [PubMed]

55. Tabata, S.; Kaneko, T.; Nakamura, Y.; Kotani, H.; Kato, T.; Asamizu, E.; Miyajima, N.; Sasamoto, S.; Kimura, T.; Hosouchi, T.; et al. Sequence and analysis of chromosome 5 of the plant Arabidopsis thaliana. Nature 2000, 408, 823-826. [PubMed]

56. Dubouzet, J.G.; Sakuma, Y.; Ito, Y.; Kasuga, M.; Dubouzet, E.G.; Miura, S.; Seki, M.; Shinozaki, K.; Yamaguchi-Shinozaki, K. OsDREB genes in rice,Oryza sativa L. encode transcription activators that function in drought-, high-salt- and cold-responsive gene expression. Plant J. 2003, 33, 751-763. [CrossRef] [PubMed] 
57. Takahashi, H.; Chen, Z.; Du, H.; Liu, Y.; Klessig, D.F. Development of necrosis and activation of disease resistance in transgenic tobacco plants with severely reduced catalase levels. Plant J. 1997, 11, 993-1005. [CrossRef] [PubMed]

58. Untergasser, A.; Cutcutache, I.; Koressaar, T.; Ye, J.; Faircloth, B.C.; Remm, M.; Rozen, S.G. Primer3-New capabilities and interfaces. Nucleic Acids Res. 2012, 40, e115. [CrossRef] [PubMed]

59. Livak, K.J.; Schmittgen, T.D. Analysis of relative gene expression data using real-time quantitative PCR and the $2^{-\Delta \Delta C t}$ Method. Methods 2001, 25, 402-408. [CrossRef] [PubMed]

60. Hood, E.E.; Gelvin, S.B.; Melchers, L.S.; Hoekema, A. NewAgrobacterium helper plasmids for gene transfer to plants. Transg. Res. 1993, 2, 208-218. [CrossRef]

61. Weigel, D.; Glazebrook, J. Transformation of Agrobacterium using electroporation. CSH Protoc. 2006, $2006,7$. [CrossRef] [PubMed]

62. Horsch, R.B.; Fry, J.; Hoffmann, N.; Neidermeyer, J.; Rogers, S.G.; Fraley, R.T. Leaf disc transformation. In Plant Molecular Biology Manual; Gelvin, S.B., Schilperoort, R.A., Verma, D.P.S., Eds.; Springer: Dordrecht, The Netherlands, 1989; pp. 63-71.

63. Arnon, D.I. Copper Enzymes in Isolated Chloroplasts. Polyphenoloxidase in $\beta$ vulgaris. Plant Physiol. 1949, 24, 1-15. [CrossRef] [PubMed]

64. Hayat, S.; Hasan, S.A.; Yusuf, M.; Hayat, Q.; Ahmad, A. Effect of 28-homobrassinolide on photosynthesis, fluorescence and antioxidant system in the presence or absence of salinity and temperature in Vigna radiata. Environ. Exp. Bot. 2010, 69, 105-112. [CrossRef]

65. Lutts, $\mathrm{S}$. NaCl-induced senescence in leaves of rice (Oryza sativa L.) cultivars differing in salinity resistance. Ann. Bot. 1996, 78, 389-398. [CrossRef]

66. Sokal, R.; Rohlf, F. The Principles and Practice of Statistics in Biological Research, 3rd ed.; W. H. Freeman: New York, NY, USA, 1995.

(C) 2017 by the authors. Licensee MDPI, Basel, Switzerland. This article is an open access article distributed under the terms and conditions of the Creative Commons Attribution (CC BY) license (http:/ / creativecommons.org/licenses/by/4.0/). 